


\title{
Is Care by Grandparents or Parents Better for Children's Non-cognitive Skills? Evidence on Locus of Control from China
}

\author{
Xiang Ao \\ Renmin University of China \\ Xuan Chen \\ Renmin University of China \\ Zhong Zhao \\ Renmin University of China and GLO
}

\begin{abstract}
This study investigates the effect of grandparental care on children's locus of control (LOC), which is an important non-cognitive skill that affects children's future development. We use data from the China Family Panel Studies, which is a nationally representative survey, and employ instrumental variables to address the endogeneity of family childcare choice. We find that children in the care of their grandparents have more external LOC than children in the care of their parents do; that is, they are more likely to attribute individual success to external factors, such as luck, fate, and family background. This finding is robust to different measures of grandparental care and different model specifications. We further examine the potential mechanisms underlying this effect. Grandparents have more external LOC than parents do, which can affect children's LOC through intergenerational transmission of LOC. Their parenting attitudes and styles are also different from parents' in that grandparents take less responsibility for children's academic performance than parents do and are less strict with children. In addition, grandparental care induces adverse effects on children's family environment.
\end{abstract}

Key words: Intergenerational Childcare, Non-cognitive Skill, Locus of Control JEL classification codes: J13

\section{Corresponding Author:}

Xuan Chen

School of Labor and Human Resources

Renmin University of China

xchen11@ruc.edu.cn 


\section{Introduction}

As the new human capital theory develops, the economics scholars are gradually recognizing the importance of non-cognitive skills in individual educational attainment and socioeconomic success (Heckman et al., 2006). Family care plays a critical role in shaping non-cognitive skills through genetics, parental investment, and growth environments (Cunha \& Heckman, 2007). Economics studies have analyzed extensively the impacts of parental care on children's non-cognitive skills (e.g., Attanasio et al., 2020; Cunha \& Heckman, 2007; Hernández-Alava \& Popli, 2017). However, with extended lifespans and changes in family arrangements, such as decreased family size and increased maternal employment, a growing number of grandparents have become involved in grandchildren's care. Such a phenomenon has become globally common and drawn academic attention. Sadruddin et al. (2019) survey 206 studies from more than 50 countries and regions globally and comprehensively review the impacts of grandparental care on children's outcomes, including physical and mental health, behaviors, cognitive skills, and education. Most of these studies are in the fields of medical science, psychology, and sociology, with only a few in economics (e.g., Conway \& Li, 2012; Del Boca et al., 2018; He et al., 2018; B. Liu et al., 2019). To address this research gap, this study analyzes the impacts of grandparental care on children's non-cognitive skills in China.

Childcare provided by grandparents has become a widespread phenomenon in many families in both urban and rural regions of China (F. Chen et al., 2011). Children in the care of grandparents analyzed in this study are different from the children left behind by rural migrants who are the subject of existing studies (e.g., B. Liu et al., 2019). While left-behind children are mainly targeted at skipped-generation households (children living with only grandparents), the households we consider in this study include both skipped-generation and multigenerational households (children living with both parents and grandparents). On the one hand, based on 2010 census data, multigenerational households accounted for $17.18 \%$ of all the household types, which remains stable compared with its proportions in 2000 and even 1982 (Wang, 2013). On the other hand, although the number of skipped-generation households has grown rapidly in recent years, the proportion remains relatively low, accounting for $2.78 \%$ in 2010 (Wang, 2013). ${ }^{1}$ The only data used in this study are from the China

\footnotetext{
The number of skipped-generation households in 2010 was $31.75 \%$ higher than that in 2000 and $192.63 \%$ higher than in 1982
} 
Family Panel Studies (CFPS), which is a nationally representative survey of Chinese families and individuals launched by Peking University in 2010, with three-generation households accounting for $50.4 \%$ of families with children under 16 years of age $(\mathrm{Q}$. Wu \& Liu, 2015). In these households, many grandparents assume responsibility for looking after their grandchildren, even when the parents live in the same household.

The reasons for grandparental care differ between urban and rural families in China. Besides traditional culture and custom, an important reason for grandparental care in rural areas is the rising number of rural-to-urban migrants. As more working-age couples migrate to urban areas for temporary employment, these couples usually have to leave their children with their elderly parents in rural villages due to the restriction of household registration and economic considerations (Wang, 2016). By contrast, because the existing public childcare system is incomplete and the market-based childcare services are imperfect in urban areas, urban couples often struggle to balance work and childcare, especially with the implementation of the comprehensive two-child policy (Y. Chen \& Sun, 2019). For these reasons, many grandparents are involved in caring for their grandchildren in China.

We investigate the effect of grandparental care on children's non-cognitive skills, with a focus on locus of control (LOC). LOC refers to a person's attitude or belief that the consequences of individual behaviors are typically either under their control (internal) or the control of the environment (external) (Rotter, 1966). In other words, an individual with an internal LOC usually attributes individual success to internal factors, for example, effort, rather than external factors, such as luck, fate, and family background. It has been well established that LOC not only affects educational attainment (e.g., Coleman \& Deleire, 2003; Heckman \& Kautz, 2012; Mendolia \& Walker, 2014), but is also associated with life behaviors in young adults, like tobacco and alcohol consumption (Cobb-Clark et al., 2014; Lassi et al., 2019), psychotic symptoms in early adolescence (Thompson et al., 2011), and labor market performance and saving behavior in adults (Cobb-Clark, 2015; Cobb-Clark et al., 2016). Furthermore, Cobb-Clark and Schurer (2013) show empirically that LOC is not truly stable over the life cycle and its changes are concentrated among the young or very old. Hence, childhood is a crucial period of LOC development, and family parenting may have important effects on its formation before a child reaches adulthood.

In this study, we examine the effect of grandparental care on the LOC of children 
aged 10 to 15 , which is the sensitive period of family care for the formation of non-cognitive skills. We use the numbers of parents' siblings as instrumental variables (IVs) to address the endogeneity of family care choice. From the three waves of the CFPS data in 2010-2014, we find that grandparental care significantly raises children's external LOC by approximately 1 standard deviation. In other words, children in the care of their grandparents tend to attribute individual success to external factors, such as luck, fate, or family background, more than children in the care of their parents do. This finding is robust to different measures of grandparental care and different model specifications. We further explore three potential mechanisms underlying this effect by fully exploiting the questionnaire information of the CPFS. First, we find evidence that grandparents on average have more external LOC than parents due to old age, which can lead to a greater level of external LOC of children through intergenerational transmission of LOC. Second, with respect to parenting attitudes and styles, grandparents are less likely to take strong responsibility for children's academic performance and are less strict about children's study and daily routines than parents are. Third, regarding family environment, grandparental care induces adverse effects on children's learning environment and children's communication with parents. Understanding these mechanisms underlying the effect could help alleviate or even eliminate the disadvantages of grandparental care on children's non-cognitive abilities.

We contribute to the existing literature in the following aspects. First, we complement the current economics literature by concentrating on the impact of grandparental care in multigenerational families on children's LOC in China. Previous economics studies usually focus on the effect of parental care on children, while the related literature on China often considers left-behind children of rural migrants who are in the absence of parental care as the research subjects. Second, our study extends the psychology literature, as we focus on children aged 10 to 15 years, which is a sensitive period for the impact of family care on the formation of children's LOC, and we provide empirical evidence on the potential mechanisms underlying the effect of grandparental care. Psychology studies usually examine the LOC of preschool children, and most of their mechanism analysis involves expository arguments. Third, different from several works from China that employ only information about a child's main caregiver in the CFPS to define grandparental care, in this study, we fully exploit the questionnaires and define different measures of grandparental care by 
supplementing the information about the primary caregiver who answered the childcare questions as a proxy parent. The primary caregiver information is matched with the rich family upbringing information in the CFPS, which benefits our mechanism analysis. Fourth, since the childcare choice is usually a joint decision made by family members within a household and thus, may suffer endogeneity, methodologically, we use the numbers of parents' siblings (brothers and sisters, separately) as IVs to address the endogeneity issue. Based on the existing literature on intergenerational transmission of LOC, we also consider a possible threat to the exclusion restriction of IVs in the presence of LOC transmission within the family.

The rest of the paper is organized as follows. Section 2 reviews the existing literature on grandparental care and children's non-cognitive skills. Section 3 introduces the CFPS data and reports summary statistics. Section 4 presents our empirical models and main results. Section 5 conducts robustness checks. Section 6 discusses the underlying mechanisms, and Section 7 concludes.

\section{Literature Review}

The economics literature has studied the impacts of family care on children's cognitive and non-cognitive abilities from many aspects, including family income (e.g., Akee et al., 2018; Dahl \& Lochner, 2012; Fletcher \& Wolfe, 2016; Khanam \& Nghiem, 2016), parental childcare (e.g., Attanasio et al., 2020; Cunha \& Heckman, 2007; Hernández-Alava \& Popli, 2017), maternal employment (e.g., Bernal, 2008; James-Burdumy, 2005), and childcare choice (e.g., Bernal \& Keane, 2011). These cited studies usually focus on the monetary and time input of parents; however, the composition of family members also affects children's physical body, psychology, behaviors, and academic performance (e.g., Conway \& Li, 2012; Del Boca et al., 2018; He et al., 2018; B. Liu et al., 2019). For example, research in psychology and social science has shown that family members other than parents also affect child development through daily-life contact (Bengtson, 2001; Jæger, 2012).

Sadruddin et al. (2019) provide a comprehensive review on the impacts of grandparental care on children and find that grandparental care takes many forms, including co-residence, frequency of visit, daily care, and financial support; each of these different caring behaviors has different impacts. For instance, Tanskanen and Danielsbacka (2018) show that frequency of visit and financial support from grandparents have no effect on children's cognitive skills and emotion, but other 
caring behaviors probably do. In this study, we focus on the impacts of the daily care of grandparents on children's non-cognitive skills.

Most of the literature on grandparental care in China focuses on its impacts on the well-being of grandparents or labor supply of parents (e.g., Y. Chen \& Sun, 2019; Yu et al., 2019). By comparison, there is limited literature on the impacts of grandparental care on children's cognitive and non-cognitive skills. Some of these studies focus on left-behind children in rural areas to examine the effects of the absence of parental care, rather than direct analyses of grandparental care. Zhang et al. (2014) collect data from a county in Hunan Province and find that the average grades of rural children decrease by 5 percentage points when both parents are not at home, and $82 \%$ of children in the sample are mainly in the care of their grandparents. Using data collected by Zhang et al. (2014), J. Wu and Zhang (2017) find that the absence of both parents is detrimental to children's cognitive and non-cognitive skills. Specifically, in the absence of both parents, children tend to have lower scores and lower self-assessment on their behavior, and are less likely to feel happy; in their sample, $71 \%$ of children live with their grandparents. Lee and Park (2010) and Jiang and Yang (2019) use a longitudinal dataset from Gansu Province and find that paternal migration has negatives effects on the psychosocial well-being of rural children; in both of their samples, approximately $20 \%$ of children live with their grandparents.

Some other studies analyze the effects of grandparental care in terms of residence arrangement. Using data from the China Health and Nutrition Survey, He et al. (2018) find that living with grandparents significantly increases children's weight, mainly through diet and physical exercise. Using CFPS 2010 data, Deng et al. (2019) examine the impacts of both residence arrangements and caring behavior on children's cognitive abilities in rural areas. They find that children of multigenerational households in the main care of grandparents have generally higher scores. However, left-behind children who live only with grandparents and children living only with their parents show no significant difference in cognitive outcomes.

According to Deng et al. (2019), co-residence seems to have effects only when grandparents are the main caregivers of children. Their results suggest that we should distinguish the impacts caused by residence arrangement and by caring behavior. Using residence arrangement as a proxy variable for grandparental care may be inaccurate, because it is possible that a grandparent is not the main caregiver of the grandchild but the receiver of family care in a three-generation household. 
Alternatively, grandparents could take care of grandchildren and be simultaneously cared for by adult children. In fact, there is often more than one caregiver of grandchildren in multigenerational households, and grandparents are involved in childcare to varying extents. Thus, it is possible that different questionnaire designs reveal information about a child's multiple caregivers. In this study, we fully exploit the questionnaires in the CFPS and define different measures of grandparental care to examine their impact on children's non-cognitive skills.

Since the concept of non-cognitive skills is borrowed from psychology, some psychology studies have found adverse influences of grandparental care on children's mental health in China (e.g., Sun \& Jiang, 2017). Our study is different from previous psychology studies on this topic in three aspects. First, we pay attention to children aged 10 to 15 years, whereas the age group studied in the psychology literature is mainly preschool children. Cunha and Heckman (2008) demonstrate that the sensitive period of family investment in children's non-cognitive skills (i.e., the period of effective impacts) is after 10 years of age. Accordingly, the impacts of grandparental care in this period may be larger than those in early childhood. In particular, Cobb-Clark and Schurer (2013) find that although LOC is relatively stable after adulthood, it changes significantly during adolescence and varies in old age. Thus, we focus on children aged 10 to 15 years, during which period the formation of LOC is sensitive to intergenerational care. Second, we adopt a large sample from a nationally representative survey, while the sample size in psychology studies is usually a few hundred. Third, we provide empirical evidence for the potential mechanisms underlying the effect of grandparental care on children's LOC. Instead, most of the discussions on underlying mechanisms are limited to expository arguments in psychology studies.

There are few economics studies on the effects of grandparental care on children's LOC. One such example is the work of Radl et al. (2017), which uses a cross-national data of 33 Organisation for Economic Co-operation and Development countries and finds that children living with grandparents have less internal LOC. However, their study neither addresses the endogeneity of residence arrangements, nor investigates the underlying mechanisms. In addition, as mentioned earlier in this section, living with grandparents is not equivalent to the caring behavior of grandparents, which may bias the estimates of the impact of intergenerational care.

In this study, we focus on the LOC of children aged 10 to 15 years and employ 
the IV method to address the endogeneity of grandparental care. We further explore three mechanisms underlying the effect of grandparental care on children's LOC, including intergenerational transmission of the LOC, the difference in parenting attitudes and styles between grandparents and parents, and the impacts on family environment. The related literature on these mechanisms is discussed in Section 6.

\section{Data and Summary Statistics}

\subsection{The Full Sample from China Family Panel Studies}

We use data from the CFPS, which represents $95 \%$ of the Chinese population in 25 provinces. Specifically, we use data from the baseline survey in 2010 and the follow-up surveys in 2012 and 2014. We exploit the child questionnaire to obtain information on childcare and children themselves, including demographic characteristics, educational attainment, and non-cognitive skills, as well information on family parenting. We also employ the adult and family questionnaires to obtain characteristics of children's parents and families, respectively.

We distinguish between two types of children's caregivers, parents and grandparents, based on two sources of information in the data. The first is directly derived from the answer to the question in the child questionnaire, "who is the main caregiver for the child in the most recent month when the parents were not on vacation?" The possible answers are a child's paternal grandparents, maternal grandparents, father, mother, babysitter, daycare, self-care, and other. The second information source is based on the identity of the adult family member who answered the childcare questions in the child questionnaire as a proxy parent. For clarity, we refer to the former as the main caregiver and to the latter as the primary caregiver. In contrast with the previous literature, which uses the question about the main caregiver in CFPS as the sole source when defining grandparental care (e.g., Deng et al., 2019; Yu et al., 2019), we use the identity of the primary caregiver to complement missing or ambiguous information about the main caregiver. More importantly, we exploit childcare information from primary caregivers to explore mechanisms underlying the effect of grandparental care.

Based on the two types of caregivers, we define the key independent variable, grandparental care $(G P C)$, in our full sample in two steps. First, as long as the answer regarding a child's main caregiver includes a grandparent, we define grandparental care of child $i$ in wave $t$ as having occurred, that is, GPC $i t=1$; however, when the 
main caregiver is only a parent and not a grandparent, it is deemed that no grandparental care has occurred, that is, $G P C_{i t}=0$. The CFPS 2012 and 2014 surveys also distinguish between childcare in the daytime and at night. However, we do not distinguish them in our context. As long as the answers include grandparents, we define grandparental care as having occurred, regardless of whether it happened in the daytime or at night. Accordingly, for observations in the 2012 and 2014 waves, it is possible that for a child with $G P C_{i t}=1$, parental care happened either in the daytime or at night. Second, if the main caregiver is neither a parent nor a grandparent, we supplement it with the identity of the primary caregiver: if the primary caregiver is child $i$ 's grandparent, $G P C_{i t}=1$; if the primary caregiver is a parent, $G P C_{i t}=0$. In Sections 5 and 6 , we employ either the main caregiver or the primary caregiver to define grandparental care and construct secondary samples for robustness checks and mechanism analysis.

Our dependent variable is children's LOC, which refers to whether an individual tends to attribute individual success to internal factors, for example, effort, or external factors, like luck, fate, and family background. The children surveyed for the LOC information differ in the three waves of the CFPS: the 2010 wave is for children aged 12 and 14 years, whereas the 2012 and 2014 waves survey those who were initially interviewed or who had been interviewed before but with missing LOC values. Since childhood after 10 years of age is a sensitive period for the formation of non-cognitive skills (Cunha \& Heckman, 2008), we focus on children aged between 10 to 15 years. By comparison, most psychology studies on LOC are concerned with preschool children, and caregivers often help answer survey questions for preschool children. In the CFPS, school-age children answer the LOC questions independently.

Following Chen et al. (2018) and Gong et al. (2017), we use seven LOC questions in the child questionnaire to construct LOC measures for each child. The seven questions explicitly ask respondents about their views on a determinant for individual success, for instance, luck, effort, hard work, and family status, which are summarized in Table $1 .^{2}$ As a first step toward creating a measure of individual LOC, we use factor analysis to identify common factors underlying the seven items. As

\footnotetext{
There are minor differences in the expressions of the questions on LOC among the three waves of the CFPS. In the 2010 wave, the question was whether the respondent agreed that a certain factor is (the most) important for future success. The answer is scaled from 1 (totally disagree) to 5 (totally agree). In the 2012 and 2014 waves, the respondent was asked to rate the role of each factor in a child's future success on a scale of 0 (least important) to 10 (most important). We multiply the answer in 2010 by 2, so that the range of the answer in 2010 can be compared with that in 2012 or 2014.
} 
shown in Figure 1, our factor analysis indicates that items 3 and 5 load onto one factor that is interpreted as internal LOC, while items 1, 2, 4, 6, and 7 load onto another factor that is interpreted as external LOC. Similar to Caliendo et al. (2015), we construct the LOC index as follows. First, we reverse the scales for the statements of internal items, so that a higher value denotes more external LOC for all statements. Next, we take the summation of the answers for these seven statements to create a continuous, one-dimensional measure of LOC with higher values denoting more external LOC and lower values denoting more internal LOC. Applying an analogous method, we create two additional indexes, one for internal LOC and the other for external LOC, in which higher scores represent higher degrees of internal and external LOC, respectively. In the regression, we normalize them to have means of 0 and standard deviations of 1 .

We pool children's LOC information of each wave together and obtain a pooled cross-sectional sample of children. Then, we merge our full sample into the children sample, and omit those children whose main caregivers and primary caregivers are neither their grandparents nor their parents (comprising $8.8 \%$ of the children sample). The final full sample contains 4,598 child-wave observations, among which 948 observations are cared for by grandparents, accounting for $20.62 \%$.

\subsection{Summary Statistics of the Full Sample}

We report the summary statistics of the LOC indexes and the control variables in Table 2. The IVs and the related variables for our mechanism analysis in Table 2 are discussed in later sections. We report the means and standard deviations of these variables in the full sample, and the differences in their means between grandparental care and parental care. Panel A shows that on average, children in the care of grandparents have more external LOC than those in the care of parents. However, children do not show significant difference in their internal LOC between the two types of childcare.

For children's characteristics, we consider gender ( $=1$ if boy), residence region (=1 if lived in an urban area for more than 6 months last year), age, education stage (=1 if no schooling, $=2$ if in primary school, $=3$ if in middle school, and $=4$ if in high school), and number of siblings. Panel B of Table 2 shows that $52.3 \%$ of children in our full sample are boys, and $39.3 \%$ of them live in urban areas. These two proportions are not significantly different between children cared for by grandparents 
and those cared for by parents. The average age of children is 12.4 years and most of them are in primary or middle school. Compared with those in the care of parents, children in the care of grandparents are younger and at earlier stages of education. The average number of siblings of children is just above 1, and children cared for by grandparents have fewer siblings than those cared for by parents.

For the characteristics of parents and households, we consider both parents' ages and years of schooling, as well as household income per capita and household size. The middle part of Panel B in Table 2 shows that children with grandparental care have younger parents and their parents have more years of schooling than those with parental care. It is probable that younger parents struggle to balance childcare and work, and that parents with higher levels of education are more likely to be occupied with their jobs. Hence, they tend to choose grandparental care. At the household level, a household with grandparental care has more income per capita and larger size. It is possible that families with better economic conditions tend to live together, and in these situations, grandparents are more likely to take care of their grandchildren.

\section{Econometric Models and Estimation Results}

\subsection{Econometric Models}

We construct the following linear model to identify the effect of grandparental care on children's LOC:

$$
Y_{i t}=\alpha_{0}+\alpha_{1} G P C_{i t}+\boldsymbol{\alpha}_{2} \boldsymbol{X}_{i t}^{\prime}+\tau_{p}+\omega_{t}+\varepsilon_{i t},
$$

where $Y_{i t}$ is child $i$ 's LOC index in wave $t$, and GPC $i t$ is our key independent variable, denoting grandparent care when it equals $1 . \boldsymbol{X}_{\boldsymbol{i t}}$ represents the control variables, including all the characteristic variables of children, parents, and households, with household income per capita transformed into $\log$ form. $\tau_{p}$ and $\omega_{t}$ represent the fixed effects of the province and the survey wave, respectively, to which child $i$ belongs. $\varepsilon_{i t}$ is the error of the model. In the estimation, we calculate clustered standard error at the county level.

We first use ordinary least squares (OLS) regression to estimate model (1), but it requires a strong exogeneity assumption to obtain the causal effect of grandparental care on children's LOC that conditional on the set of control variables (including province and wave fixed effects), no confounders affect both childcare choice and a child's LOC. The endogeneity issue, however, is almost inevitable because it is common for family members within a household to make joint decisions on the childcare choice. It is quite likely that unobserved household factors (e.g., preference 
or habit of a family) or events (e.g., a child suffered from a certain disease) confound both the childcare choice and a child's LOC. Reverse causality might also occur when a child with more external LOC tends to depend on their family, and thus, demands grandparental care when parental care is unavailable. In model (1), we incorporate the characteristics of children's parents and households to alleviate the endogeneity. For instance, parents' education attainment may influence children's LOC through education investment and parenting style and may also influence the caring behaviors of grandparents. Similarly, parents' age, which is highly associated with mothers' childbearing age, may influence the formation of children's non-cognitive skills and simultaneously affect the childcare choice.

In addition to controlling the characteristics of parents and households, we employ the IV method to further address the endogeneity caused by the unobserved confounders. The existing literature on grandparental care usually constructs IVs based on family structure, for example, parents' siblings or grandparental characteristics. In our context, we choose IVs that have an effect on the childcare choice, but no direct effect on children's non-cognitive skills. Similar to He et al. (2018), we employ numbers of parents' brothers and sisters as two separate IVs for the following reasons. First, the numbers of parents' siblings are determined before the household makes its childcare decision and are factors that influence the childcare choice (Aassve et al., 2012). Out of concern for equity inside one family, the more siblings a pair of parents has, the less likely it is for the grandparents to take care of the children. As shown in Panel $\mathrm{C}$ of Table 2, the numbers of parents' siblings in a household with grandparental childcare are statistically smaller than those with parental care in our full sample, which is consistent with this argument. Second, the previous literature finds that dependence of elderly people on adult children has strong gender preference in China (Guo, 2002), and thus, the numbers of sons and daughters may have different impacts on the childcare choice. If we added the numbers of parents' brothers and sisters together to construct one IV, we would assume that the effects of the numbers of brothers and sisters on the childcare choice would be equal. Finally, regarding the exclusion restriction of IVs, we assume that after controlling parents' ages and education attainments, as well as household characteristics, the numbers of parents' brothers and sisters hardly have a direct effect on children's LOC. Therefore, in the two-stage least squares (2SLS) estimation, we adopt the following first-step regression: 


$$
G P C_{i t}=\beta_{0}+\boldsymbol{\beta}_{\mathbf{1}} \boldsymbol{Z}^{\prime}{ }_{i t}+\boldsymbol{\beta}_{\mathbf{2}} \boldsymbol{X}_{i t}^{\prime}+\tau_{p}+\omega_{t}+\mu_{i t}+\varepsilon_{i t},
$$

where $\boldsymbol{Z}_{i t}$ represents the IVs, including the number of parents' brothers and sisters.

\subsection{Main Estimation Results}

Table 3 represents our estimation results for the effect of grandparental care on children's LOC, measured by the full, external, and internal LOC indexes. We first estimate Equation (1) by simple OLS regression, treating the childcare choice as an exogenous variable. The results of Column (2) show that grandparental care has a significantly positive effect on a child's LOC full index, indicating that children cared for by grandparents are more likely to attribute individual success or attainment to external factors instead of internal factors than are children cared for by parents. The OLS estimation results also show that on average, older children and children at higher-stage education have less external LOC, whereas children with more siblings have more external LOC. It is possible that siblings of a child provide some assistance during the child's growth, leading to more external LOC of the child. For parents' and households' characteristics, parents with higher education levels and households with more income per capita tend to have children with less external LOC.

Next, we estimate Equation (1) by the 2SLS estimation, with the first-stage regression as specified in Equation (2). As shown in Column (1) of Table 3, our IVs perform well in the first-stage regression with the expected signs. After controlling all the control variables, we find that the numbers of parents' brothers and sisters both negatively and significantly affect the probability of grandparental care, and that the absolute value of the coefficient of the number of brothers is larger than that of the number of sisters $(0.029$ vs. 0.017). This finding is credible in the Chinese context. First, if adults have more siblings, then the responsibility of caring for elderly parents can be shared among more siblings, leading to a lower likelihood of caring for grandchildren. As a result, the signs of both IVs are negative in the first stage. Second, traditionally, sons are mainly responsible for supporting their elderly parents in China, whereas married daughters usually have no such obligation. This explains why the coefficient of the number of brothers is larger in the absolute value than that of the number of sisters. At the bottom of Table 3, we show the weak IV test and the over identification test for the 2SLS estimation. The Kleibergen-Paap rank Wald F-statistics is 25.86 , above the critical value at the $10 \%$ level (10\% maximal IV size: 19.93), indicating that the IVs we employ are highly correlated with grandparental 
care and excluding the weak IV issue at the $10 \%$ level. The Hansen J test P-value is 0.49 , indicating that the over identification restrictions are not rejected. ${ }^{3}$

The 2SLS estimates on the full LOC index are shown in Column (3) of Table 3. Compared to the OLS estimation, the coefficient of grandparental care on children's LOC full index becomes much larger and remains significantly positive. The estimated coefficients of the other control variables are similar to those in Column (2), except for the coefficient of the number of a child's siblings and that of the household size. The former becomes larger and the latter becomes negative; these results are consistent with the signs of their respective coefficients in the first-stage estimation. Both the OLS and 2SLS estimation results confirm that children in the care of grandparents have more external LOC than do children in the care of parents, that is, children in the care of grandparents tend to believe that individual success or attainment depends on external rather than internal factors. The 2SLS estimate shows that grandparental care increases a child's full LOC index by approximately 1.14 standard deviations, which is economically significant. By contrast, the OLS regression probably underestimates the effect.

Columns (4) and (5) and Columns (6) and (7) in Table 3 report the estimated effects on children's external and internal indexes, respectively. The coefficients of grandparental care on the external index are positive and significant, confirming that grandparental care renders children more external. The coefficients of the control variables in Columns (4) and (5) are also similar to those in Columns (2) and (3). By contrast, the estimated effects of grandparental care on the internal index are negative and statistically insignificant, indicating that grandparental care barely affects children's internal LOC. The coefficients of the control variables also become insignificant, except that a father' education is marginally associated with more internal LOC of his child. Therefore, according to Table 3, we find that grandparental care increases children's tendencies to have external LOC, but has no effect on children's internal LOC.

\section{Robustness Checks}

\subsection{Different Measures of Locus of Control}

\footnotetext{
${ }^{3}$ We have conducted the weak IV test and the over identification test on each of our 2SLS estimation results throughout this paper. The Kleibergen-Paap rank Wald F-statistics is above the critical value at the $10 \%$ significant level (10\% maximal IV size: 19.93), and the Hansen J test P-value is above 0.1 for all the estimation. We omit these test results in the main text, but they are available in the corresponding tables.
} 
In this section, we conduct four robustness checks to support our main finding that grandparental care leads to more external LOC of children. First, we consider different measures of LOC by using each statement summarized in Table 1 as separate measures. Table 4 shows the estimated effects of grandparental care on each component of LOC by the OLS and 2SLS estimations. In general, compared to those cared for by parents, children cared for by grandparents tend to rate external factors that are out of their control more importantly than internal factors. For instance, they are more likely to attribute future success to social status, connections of the family, talent, or luck, and are less likely to believe that effort is an important determinant in individual success. Thus, the estimates on the LOC indexes (Table 3) and on each component of LOC (Table 4) are consistent, confirming that grandparental care makes children have more external LOC.

\subsection{Different Measures of Grandparental Care}

Next, we use alternative measures of grandparental care in secondary samples for a robustness check. We first define grandparental care by using only the question about the main caregiver in the child questionnaire. Under this definition, we drop observations whose main caregiver contains neither parents nor grandparents and do not supplement them with the primary caregiver information. The main caregiver sample contains 3,190 child-wave observations, among which 807 children are in the care of grandparents, comprising $25.3 \%$ of the main caregiver sample.

Table 5 shows the OLS and 2SLS estimation results using the main caregiver sample. Consistent with the results in the full sample, the estimated effects of grandparental care on children's LOC full and external indexes are positive and statistically significant, while the effect on the internal index is insignificant. The positive effects on the full and external indexes become smaller than those in the full sample, probably because more than one-fourth of the observations in the full sample are dropped. As a result, the proportion of children cared for by grandparents and by parents at different times (either in the daytime or at night) becomes larger in the main caregiver sample, diluting the effect of grandparental care on children's external LOC.

We next define grandparental care only according to the identity of the primary caregiver who answered childcare questions in the child questionnaire as a proxy parent. Under this definition, we drop observations whose primary caregiver is neither a parent nor a grandparent. The primary caregiver sample contains 4,474 child-wave 
observations, among which 610 children are cared for by grandparents, accounting for $13.63 \%$. The lower proportion of grandparental care in the primary caregiver sample than those in the full and main caregiver samples is because the primary caregiver identity employs a stricter definition of grandparental care. In a household with three generations living together, family members usually share the duty of childcare, and sometimes it may be difficult to distinguish who is the main caregiver of the child. If a parent answered the childcare questions as the primary caregiver, it is still possible that they regarded some other household member, for example, a grandparent, as the main caregiver, especially when the 2012 and 2014 waves distinguish the main caregiver in the daytime and at night.

Table 6 shows the OLS and 2SLS estimation results in the primary caregiver sample. The estimation results conform to those in the full sample, and the estimated positive effects of grandparental care on children's full and external LOC indexes become even larger than those in the full sample, which is consistent with the stricter definition of grandparental care in the primary caregiver sample, largely precluding the latent effect of parental care underlying the other two measures of grandparental care. Thus, Tables 5 and 6 verify the positive effect of grandparental care on children's external LOC, regardless of the specific measures of grandparental care we adopt.

\subsection{Controlling County Fixed Effects}

For the third robustness check, we estimate the effect of grandparental care on children's full LOC index by controlling county fixed effects, instead of controlling province fixed effects in Equation (1). It is possible that unobserved factors at the county level affect both family childcare choice and children's LOC (e.g., customs of a county). As shown in Table 7, in all the three samples we consider, the OLS and 2SLS estimation results with county fixed effects controlled are similar to the corresponding ones with province fixed effects controlled. The OLS estimates decrease slightly, and the 2SLS estimates remain almost the same. Thus, our main finding that grandparental care increases children's external LOC is robust to controlling county fixed effects.

\subsection{Addressing the Potential Threat of Instrumental Variables}

As our final robustness check, we consider a potential threat of our IVs - intergenerational transmission of LOC within the family. The validity of our 
IVs relies on the exclusion restriction that, conditional on all the covariates, the number of parents' siblings affects children's LOC only through the channel of grandparental care. The existing literature, however, has documented intergenerational transmission of non-cognitive skills in developed countries (e.g., Anger, 2012; Dohmen et al., 2012; Eaves et al., 1999; Gauly, 2017). In particular, Ao et al. (2019) use CFPS data and find solid empirical evidence of intergenerational transmission of LOC in China. Specifically, Ao et al. (2019) demonstrates the existence of direct transmission of LOC from parents to children, transmission from surrounding people to children, and parents' positive assortative mating based on LOC, which reinforces intergenerational transmission from parents to children. Thus, our IVs would violate the exclusion restriction if the number of siblings could affect individual LOC, or if parents' LOC were associated with the number of their children, although the existing literature has not shown such evidence. In that case, the more siblings a pair of parents has, the more likely is the parents' or grandparents' LOC to be influenced, and the more likely is the occurrence of intergenerational transmission of LOC from parents to children and transmission from surrounding grandparents to children.

Based on this reasoning, we add the average level of LOC of all adult members within a household to our model for a robustness check. We choose the average LOC of a household rather than that of parents for three reasons. First, only approximately one-half of the observations in the full sample have both parents' LOC. Second, children cared for by grandparents are more likely to have missing values of parents' LOC in the full sample. If we used parents' average LOC, a sample selection issue would emerge. Third, according to Ao et al. (2019), a child's surrounding people, including grandparents, can also transmit their LOC to the child.

We employ two sources of information to construct the average LOC at the household level. One is the primary caregiver's LOC from the childcare section of the child questionnaire, and the other is the respondent's LOC from the adult questionnaire. The items in both questionnaires are the same as those for children's LOC summarized in Table 1. Primary caregivers' LOC is available only for those who take care of children aged 4, 8, or 12 years in 2010 and 2012 and for those who were initially interviewed in 2014 or had been interviewed before but with missing values of LOC information. Respondents' LOC from the adult questionnaire is available only for 2010. We construct the average LOC at the household level in the following way. We first calculate the average LOC of the primary caregivers in a household of each 
wave. $^{4}$ Next, if the primary caregivers' average LOC is missing, we supplement it with the average LOC of all adults within a household from the 2010 survey. ${ }^{5}$ Finally, we construct the LOC index at the household level using the same method applied to children's LOC full index.

We report the OLS and 2SLS estimation results on the LOC full index by controlling the average LOC at the household level in Table 8, with Columns (1) and (3) replicating the results in Columns (2) and (3) in Table 3, respectively. Consistent with Anger (2012) and Ao et al. (2019), we verify the positive association between a family's LOC and the child's LOC. Although the OLS and 2SLS estimates of the grandparental care effect decrease slightly, these coefficients remain positive and statistically significant, indicating that given the possibility that the number of parent's siblings might influence children's LOC through transmission of LOC within the household, grandparental care still has a positive effect on children's external LOC. Therefore, our main finding is robust to the potential violation of the exclusion restriction, and we conclude that grandparental care increases children's external tendencies.

\section{Potential Mechanism Analysis}

\subsection{Intergenerational Transmission of Non-cognitive Skills}

In this section, we explore the potential mechanisms or channels through which grandparental care affects children's LOC differently from parental care. First, it is possible that a caregiver directly transmits their non-cognitive skills to the child. Bisin and Verdier (2000) present a seminal model of intergenerational transmission of non-cognitive skills through family socialization and marital decisions. Family socialization affects not only intergenerational transmission of economic preferences between parents and children (e.g., Dohmen et al., 2012), but also transmission between family members (Kimball et al., 2009). Accordingly, if grandparents have more external LOC than parents, it is possible that children in the care of grandparents have more external LOC than do those in the care of parents through intergenerational transmission of LOC.

Psychologists have devoted a great deal of effort to understanding the dynamic

\footnotetext{
${ }^{4}$ If a household has more than one child, the primary caregiver's LOC is asked for each child.

5 Ideally, we should use only adults' LOC to construct the average LOC at the household level. In that case, the sample size would become much smaller after we match the average LOC with our children sample.
} 
tendency of LOC through the life cycle, and they generally agree that LOC evolves over the life cycle as an individual's physical and mental health changes (Gatz \& Karel, 1993). Phares (1976) stated, "With advanced age, one may revert toward the helplessness of childhood. If so, we would expect the elder, as a group, to exhibit more external beliefs."(p.159) It is intuitively plausible that the elderly become more external as their health status declines and social activities decrease. Some literature has shown empirical evidence that elderly people are more external than younger people. For example, Ryckman and Malikiosi (1975) and Cicirelli (1980) find that there is a gradual decrease in internal LOC after adults turn 60 years of age. Lumpkin (1986) uses a nationally representative US sample of individuals aged 25 to 83 to find that the elderly (65 years or older) indeed have more external LOC than do younger people. In addition, based on a family follow-up survey in Australia, Cobb-Clark and Schurer (2013) find a substantial increase in the tendencies of external LOC among the elderly.

We provide evidence on the mechanism of intergenerational transmission of LOC in two steps. We first testify the relationship of individual LOC and age using the CFPS data. As we have only information of one primary caregiver for every child in a household, either the parent or grandparent, we cannot compare a parent's LOC to a grandparent's LOC for the same child. Thus, we test this relationship within one household by using the respondents' LOC from the adult questionnaire in the CFPS 2010. In the OLS regression on adults' full LOC index, we control age, gender, log of individual income, years of schooling, marriage status, and household fixed effects, with standard errors clustered at the household level.

Table 9 reports the association between age and individual LOC in three different measures of ages. With age being a continuous variable, Column (1) shows that an adult's external LOC rises as they age. In our primary caregiver sample, the average age of parents is 39.9 years and of grandparents is 64.2 years. Thus, we further compare adults' LOC full index in different age groups. Column (2) shows that compared to adults under 50 years of age, the full index of adults over 50 years is higher by 0.141 standard deviations, indicating more external LOC. Column (3) shows the results with more age groups: under 40, 40-49, 50-59, and over or equal to 60. Adults under 40 years have the least external LOC among the four age groups, and the full index of elders over or equal to 60 years is higher by 0.194 standard deviations than that of adults under 40 years. Therefore, Table 9 verifies the positive 
association between age and adults' external LOC in the CFPS data and provides indirect evidence that within a household, grandparents have more external LOC than parents do.

Second, based on our primary caregiver sample, we incorporate the LOC of the primary caregiver into our model to examine the mechanism of intergenerational transmission of LOC. Owing to the relative stability of adults' LOC (before old age), we supplement missing values of the primary caregivers' LOC with adults' LOC from the 2010 survey to obtain a large sample size. In Table 2, the first row of Panel D reports the mean of primary caregivers' LOC and the difference between grandparents and parents as caregivers. On average, grandparents have more external LOC than parents by 0.272 standard deviations, and the difference is statistically significant.

Table 10 reports the OLS and 2SLS estimation results on children's LOC full index in our primary caregiver sample, with the primary caregiver's LOC being an additional covariate. Columns (1) and (3) replicate the results in Columns (1) and (2) of Table 6, respectively. The positive association between a primary caregiver's LOC and the child's LOC demonstrates intergenerational transmission. The coefficients of grandparental care in the OLS and 2SLS estimation decrease after controlling the primary caregiver's LOC, but both remain statistically positive. In particular, the 2SLS estimate of grandparental care declines from 1.249 to 0.987 , by $21 \%{ }^{6}$ Therefore, we find evidence that the positive effect of grandparental care on children's external LOC works in part through the intergenerational transmission of LOC from primary caregivers to children.

\subsection{Parenting Attitudes and Styles}

A second potential mechanism we consider is that grandparents and parents may hold different parenting attitudes and styles, which may influence children's LOC. Parenting attitudes and styles are crucial to children's development and play even more significant roles than family economic conditions do (Doepke et al., 2019; A. Liu \& Xie, 2015). ${ }^{7}$ An extensive literature has established that parenting attitudes are

\footnotetext{
${ }^{6}$ The slight decrease in the 2SLS coefficient of grandparental care in Table 8 is consistent with our mechanism analysis of the intergenerational transmission of LOC from primary caregivers to children. Owing to insufficient observations of adults' LOC that could be matched with children's LOC (see footnote 5), we construct the average LOC at the household level by adopting primary caregivers' LOC in the first step.

${ }^{7}$ Parenting attitudes generally refer to the attitudes shown by parents in the caring and upbringing process of their children. Parenting styles refer to general strategies that parents follow during the process of raising children. The three traditional parenting styles in development psychology are permissive parenting, authoritarian
} 
an important determinant of children's mental health and personality development (e.g., Anderson \& Hughes, 1989; Jung et al., 2018). While studies in psychology and sociology have discussed the impacts of parenting styles on children's development (e.g., Chan \& Koo, 2011; Smetana, 2017), some economic works have gradually paid attention to this topic. For example, Dooley and Stewart (2007) find noticeable effects of parenting styles on children's emotions and behaviors in US families. Using CFPS data, Zhang and Qin (2019) find positive effects of both parental demandingness and responsiveness on Chinese children's academic performance and a positive association between parental responsiveness and children's mental health.

Rotter (1966), in the author's early works, speculates that parenting behaviors and LOC are related. Some psychology literature has documented that family parenting indeed impacts children's LOC. For example, close parental monitoring (Ahlin, 2014), parental supervision time (Ahlin \& Lobo Antunes, 2015), and more parental warmth (Crandall \& Crandall, 1983) are significant predictors of internal orientation, whereas less parental warmth can induce the formation of external LOC (Spokas \& Heimberg, 2008). Regarding parenting styles, adolescents who perceive their parents as being authoritative have more internal LOC than those who perceive their parents as being either permissive or authoritarian (McClun \& Merrel, 1998).

To investigate this potential channel, we compare parenting attitudes and styles between grandparents and parents by use of childcare information from the primary caregiver. We construct a measure for parenting attitude according to the statement, "I feel strong responsibility for the child's academic performance." The primary caregiver is asked to rate the extent of their agreement with the statement on a scale of 1 (totally agree) to 5 (totally disagree). The parenting attitude information is available in the waves of 2010 and 2012 only for primary caregivers who took care of children aged 1, 5, 9, or 13, and in 2014 for those who had not answered this item in the previous waves and who were initially interviewed. We match this information with children aged 10 to 15 whose primary caregivers are either grandparents or parents. ${ }^{8}$

Similar to Cui et al. (2019), we construct two variables to measure parenting styles. The first variable measures how a primary caregiver reacts to a lower score than their expectation in the child's transcript. The variable is binary, indicating

parenting, and authoritative parenting (Baumrind, 1967).

${ }^{8}$ Due to the large difference in children's age, we do not match the parenting attitude variable with our primary caregiver sample, which is limited to children aged 10 to 15 with their LOC information. 
whether the primary caregiver takes a positive action or not. We define positive actions as contacting the teacher, encouraging the child to study harder, or helping the child more; non-positive actions include physical punishment, scolding the child, restricting the child's activities, and no action. The second variable measures how a primary caregiver cares about the child's schooling and life. The variable is an index variable constructed by using six survey items regarding the frequencies of childcare behaviors, for example, how often the primary caregiver gives up watching TV shows to avoid disturbing the child's study, and how often the caregiver discusses what is happening at school with the child. ${ }^{9}$ We first reverse the scales of the frequencies so that for all the items, a higher score denotes caring more about the child, and then we sum up the responses to all the items to construct the index. As the CFPS asks parenting style questions for all school-age children in each wave, we match the parenting style variables with our primary caregiver sample. As shown in Panel D of Table 2, on average, grandparents are less likely to take positive actions in response to children's lower school grades and to care less about children's schooling and life than parents are. The differences in parenting styles between them are statistically significant.

Table 11 shows the differences in parenting attitudes and styles between grandparents and parents using OLS estimation. In the regression, we normalize the parenting attitude variable (responsibility for a child's academic performance) and the parenting style index variable (caring about a child's schooling and life), as well as each item for the latter, with means of 0 and standard deviations of 1 by each wave. The estimation results show that grandparents are less likely than parents to agree that they assume strong responsibility for children's low academic performance, to take positive actions in response to children's low school grades, and to care about children's schooling and life. In particular, the parenting style index of grandparents is lower than that of parents by -0.342 standard deviations. To explain such a large difference, we further examine each item of the parenting style index, as shown in Table 12. The estimates of grandparental care on each component remain negative and

\footnotetext{
${ }^{9}$ The six survey items include: (1) "How often do you give up watching TV shows you liked to avoid disturbing your child when he/she is studying?" (2) "How often do you discuss what happens at school with your child since this semester started or how often did you do so in the last semester?" (3) "How often do you ask your child to finish homework?"(4) "How often do you check the child's homework?" (5) "How often do you restrict the child from watching TV?" and (6) "How often do you restrict the types of TV programs the child can watch?" The primary caregivers are asked to rate the frequency on a scale of 1 (very often, 6-7 times a week) to 5 (never) in the CFPS.
} 
statistically significant, except that on giving up watching TV. The large difference in the parenting style index between grandparents and parents is mainly driven by two behaviors: discussion with children on their situation at school and checking their homework. Hence, the results in Table 12 confirm the noticeable divergence in parenting styles between parents and grandparents. The results on parenting styles also hold when we match the two variables with children between 10 and 15 years of age whose primary caregivers are either grandparents or parents (see Appendix A1 and A2). ${ }^{10}$

In summary, we find divergent parenting attitudes and styles between parents and grandparents. Parents tend to take responsibility for children's academic performance, to take positive actions in response to children's lower grades, and to care more about children's study and daily life. By contrast, grandparents are more likely than parents to be permissive. Such divergence is another potential mechanism that underlies the effect of grandparental care on children's LOC.

\subsection{The Impact on Family Environment}

Grandparental care may affect children's LOC through its impact on family environment, which is the third mechanism we consider. The economics literature has documented that family environment has an important impact on children's development (Carneiro et al., 2013; Desai et al., 1990), especially on the formation of children's non-cognitive skills (Cunha \& Heckman, 2009). Some psychology studies have discussed the impacts of family environment on children's LOC. For example, a harsh and rejecting family environment can strengthen the formation of children's external LOC (Enger et al., 1994; Moilanen \& Shen 2014; Phares, 1976), and inadequate maternal interaction with children is associated with an increasing risk of children being externally oriented (Nowicki et al., 2018). By contrast, a warm and supportive relationship with parents or more encouragement from mothers is correlated with children's internal LOC (Carton \& Nowicki, 1994; Carton et al., 1996).

We construct two variables to describe family environment. As a measure for children's learning environment at home, we first use a binary variable to indicate whether or not any family member tutors the child for her homework. Then, we

\footnotetext{
${ }^{10}$ Table 12 and Columns (2) and (3) in Table 11 are based on our primary caregiver sample, namely, children aged 10 to 15 years with non-missing value of LOC information.
} 
construct a second index variable to measure the communication atmosphere of a household. During the survey, the interviewer of the CFPS is asked to observe the respondent's home environment and then to rate the extent of their agreement with the statement, "The parents take the initiative to communicate with the child," on a scale of 1 (totally agree) to 4 (totally disagree). We reverse the scales so that a higher score denotes a favorable communication atmosphere for the child. These two family environment variables are available for all school-age children in each wave, and thus, we match them with our full sample. As shown in the last two rows of Table 2, children cared for by grandparents are less likely to have a family member tutor for their homework, although the difference is statistically insignificant. On average, they also have a less favorable communication atmosphere with parents than those cared for by parents by 0.131 standard deviations.

Table 13 reports the OLS and 2SLS estimates of the effects of grandparental care on family environment. We normalize the communication atmosphere index with a mean of 0 and a standard deviation of 1 by wave in the regression. Columns (1) and (2) show the estimated effects on children's learning environment. The OLS and 2SLS estimates indicate that grandparental care decreases the probability of having a family member tutored for homework compared to parental care by 10.5 percentage points and 33.2 percentage points, respectively. Columns (3) and (4) show the estimated effects on communication with parents. The OLS and 2SLS estimates indicate that children in the care of grandparents have a less favorable communication atmosphere with parents than do those in the care of parents by 0.242 and 0.838 standard deviations, respectively. The results also hold when matching the variables with children aged between 10 and 15 years whose caregivers are either grandparents or parents (see Appendix Table A3). ${ }^{11}$ We find evidence that grandparental care induces adverse effects on children's family environment, which may strengthen children's external LOC.

\section{Conclusion}

We examine the impact of grandparental care on the non-cognitive skills of children and further explore its underlying mechanisms. Based on three waves of the CFPS from 2010 to 2014, we focus on the LOC of children aged 10 to 15 years, and

\footnotetext{
${ }^{11}$ The measure of grandparental care used in Appendix Table A3 follows the one in our full sample.
} 
fully exploit the information in the questionnaires to define different measures of grandparental care, which also benefits the potential mechanism analysis. We concentrate on caring behavior provided by grandparents instead of co-residence arrangements and employ the number of parent's siblings (brothers and sisters, separately) as the IVs to address the endogeneity of the childcare choice. We complement existing economics research by considering the effect of grandparental care on children's LOC with a special focus on China and provide empirical evidence for the underlying mechanisms.

Our findings demonstrate that grandparental care increases a child's external LOC by around 1 standard deviation, which is robust to specific dimensions of LOC and different measures of grandparental care. We explore the underlying mechanisms in three aspects, including intergenerational transmission of LOC, parenting attitudes and styles, and family environment. Grandparents on average have more external LOC than parents due to old age, which can affect children's LOC through the intergenerational transmission from caregivers to children. Grandparents are less likely than parents to agree that they take responsibility for children's academic performance, are less strict, and are more permissive to children. In addition, grandparental care induces adverse effects on children's learning environment and their communication with parents.

Childhood is a critical period for the formation of LOC (Kulas, 1996). LOC in childhood can affect academic performance in adolescence and labor market performances and social activities during adulthood. When children believe that their own efforts or other internal factors are determinants of individual development, it is more likely that they are able to face challenges and difficulties bravely in daily life. Conversely, if children believe that individual outcomes are mainly driven by external factors, they might remain in a passive and disadvantaged state. Psychology research has shown that children's external LOC is associated with poor academic performance, depression, and delinquency (e.g., McCauley et al., 1988; Nowicki et al., 2019; Parrott \& Strongman, 1984). These studies also have found that the impact of intergenerational care on children's non-cognitive skills lasts until they go to college (Shi et al., 2017).

Therefore, the impacts of grandparental care on children's external LOC may result in a series of adverse effects on children's future development, which requires parents to pay close attention to the results. To alleviate these disadvantages, our 
mechanism analyses provide some policy implications. It is recommended that grandparents be helped to adjust their parenting attitudes and styles by offering them modern parenting knowledge and methods through communities, media, or the internet. We also suggest that parents take the initiative to communicate with children and offer them a favorable learning environment and warm family atmosphere, even under the care of grandparents.

\section{References}

Ao X. Chen X., and Zhao, Z. 2019. The Intergenerational Transmission of Personality Traits: Evidence on Locus of Control and Trust. Studies in Labor Economics, 7(3), 29-55. (In Chinese)

Aassve A., Arpino B., Goisis A. 2012. Grandparenting and Mothers' Labour Force Participation: A Comparative Analysis Using the Generations and Gender Survey[J]. Demographic Research, 27(3): 53-84.

Ahlin E. M. 2014. Locus of Control Redux: Adolescents' Choice to Refrain From Violence[J]. Journal of Interpersonal Violence, 29(14): 2695-2717.

Ahlin E. M, Lobo Antunes M. J. 2015. Locus of Control Orientation: Parents, Peers, and Place[J]. Journal of Youth and Adolescence, 44(9): 1803-1818.

Akee R., Copeland W., Costello E.J., et al. 2018. How does household income affect child personality traits and behaviors?[J]. American Economic Review , 108(3): 775-827.

Anderson M., Hughes H. M. 1989. Parenting Attitudes and the Self-Esteem of Young Children[J]. The Journal of Genetic Psychology, 150(4): 463-465.

Anger S. 2012. The Intergenerational Transmission of Cognitive and Non-Cognitive Skills during Adolescence and Young Adulthood. IZA Working Paper, No.5749.

Attanasio O., Cattan S., Fitzsimons E., et al. 2020. Estimating the Production Function for Human Capital: Results from a Randomized Controlled Trial in Colombia[J].American Economic Review, 110(1): 48-85.

Baumrind D. 1967. Child care practices anteceding three patterns of preschool behavior[J]. Genetic psychology monographs, 75(1): 43-88.

Bengtson V. L. 2001. Beyond the Nuclear Family: The Increasing Importance of Multigenerational Bonds[J]. Journal of Marriage and Family, 63(1): 1-16.

Bernal R. 2008. The Effect of Maternal Employment and Child Care on Children's Cognitive Development[J]. International Economic Review, 49(4): 1173-1209.

Bernal R., Keane M. P. 2011. Child Care Choices and Children's Cognitive Achievement: The Case of Single Mothers[J]. Journal of Labor Economics, 29(3): 459-512.

Bisin A., Verdier T. 2000. "Beyond the Melting Pot": Cultural Transmission, Marriage, and the Evolution of Ethnic and Religious Traits[J]. Quarterly Journal of Economics, 115(3): 955-988.

Caliendo M, Cobb-Clark D A, Uhlendorff A. 2015. Locus of Control and Job Search Strategies[J]. Review of Economics and Statistics, 97(1): 88-103.

Carneiro P., Meghir C., Parey M. 2013. Maternal Education, Home Environments, and the Development of Children and Adolescents[J]. Journal of the European Economic Association, 
11: $123-160$.

Carton J. S., Nowicki S. 1994. Antecedents of Individual Differences in Locus of Control of Reinforcement: A Critical Review[J]. Genetic, Social, and General Psychology Monographs, 120(1): 31-81.

Carton J. S., Nowicki S., Balser G. M. 1996. An Observational Study of Antecedents of Locus of Control of Reinforcement[J]. International Journal of Behavioral Development, 19(1): 161-175.

Chan T. W., Koo A. 2011. Parenting Style and Youth Outcomes in the UK[J]. European Sociological Review, 27(3): 385-399.

Chen F., Liu G., Mair C. A. 2011. Intergenerational Ties in Context: Grandparents Caring for Grandchildren in China[J]. Social Forces, 90(2): 571-594.

Chen, Y. and Sun, W. 2019. The Health Consequences of Grandpareting and Histroy among Chinese: Evidence from Harmonized CHARLS Data[J]. Population Journal, 5: 45-56. (in Chinese)

Chen Y., Lu Y., Xie H. 2018. Education and Non-Cognitive Skills. Lee Kuan Yew School of Public Policy Research Paper, No.18-05.

Cicirelli V. G. 1980. Relationship of Family Background Variables to Locus of Control in the Elderly[J]. Journal of gerontology, 35(1): 108-114.

Cobb-Clark D. A. 2015. Locus of Control and the Labor Market[J]. IZA Journal of Labor Economics, 4(2):1-19.

Cobb-Clark D. A., Kassenboehmer S. C., Schurer S. 2014. Healthy Habits: The Connection between Diet, Exercise, and Locus of Control[J]. Journal of Economic Behavior \& Organization, 98: 1-28.

Cobb-Clark D. A., Kassenboehmer S. C., Sinning M. G. 2016. Locus of Control and Savings[J]. Journal of Banking \& Finance, 73: 113-130.

Cobb - Clark D. A., Schurer S. 2013. Two Economists' Musings on the Stability of Locus of Control[J]. Economic Journal, 123(570): 358-400.

Coleman M., Deleire T. 2003. An Economic Model of Locus of Control and the Human Capital Investment Decision[J]. Journal of Human Resources, 38(3): 701-721.

Conway K. S., Li M. 2012. Family structure and child outcomes: a high definition, wide angle "snapshot"[J]. Review of Economics of the Household, 10(3): 345-374.

Crandall, V. C., and Crandall, B. W. 1983. "Maternal and Childhood Behaviors as Antecedents of Internal-External Control Perceptions in Young Adulthood," in Research with the Locus of Control Construct. Development and Social Problems, Vol. 2, ed. H. M. Lefcourt. New York, NY: Academic Press: 53-106.

Cui Y., Liu H., Zhao L. 2019. Mother's Education and Child Development: Evidence from the Compulsory School Reform in China[J]. Journal of Comparative Economics, 47(3): 669-692.

Cunha F., Heckman J. J. 2007. The Technology of Skill Formation[J]. American Economic Review, 97(2): 31-47.

Cunha F., Heckman J. J. 2008. Formulating, Identifying and Estimating the Technology of Cognitive and Noncognitive Skill Formation[J]. Journal of human resources, 2008, 43(4): 738-782.

Cunha F., Heckman J. J. 2009. The Economics and Psychology of Inequality and Human Development[J]. Journal of the European Economic Association, 7(2-3): 320-364. 
Dahl G. B., Lochner L. 2012. The Impact of Family Income on Child Achievement: Evidence from the Earned Income Tax Credit[J]. American Economic Review, 102(5): 1927-1956.

Del Boca D., Piazzalunga D., Pronzato C. 2018. The Role of Grandparenting in Early Childcare and Child Outcomes[J]. Review of Economics of the Household, 16(2): 477-512.

Deng L., Li H., Liu Z. 2019. The Impact of Family Co-Residence and Childcare on Children's Cognitive Skill. IZA Working Paper, No.12421.

Desai, Sonalde, Robert T. Michael and P. Lindsay Chase-Lansdale. 1990. Home Environment: A Mechanism through which Maternal Employment Affects Child Development.Working Paper,No. 20, The Population Council, New York.

Doepke M, Sorrenti G, Zilibotti F. 2019. The Economics of Parenting[J]. Annual Review of Economics, 11(1): 55-84.

Dohmen T., Falk A., Huffman D., et al. 2012. The Intergenerational Transmission of Risk and Trust Attitudes[J]. Review of Economic Studies, 79(2): 645-677.

Dooley M., Stewart J. 2007. Family Income, Parenting Styles and Child Behavioural-Emotional Outcomes[J]. Health Economics, 16(2): 145-162..

Eaves L., Heath A., Martin N., et al. 1999. Comparing the Biological and Cultural Inheritance of Personality and Social Attitudes in the Virginia 30000 Study of Twins and their Relatives[J]. Twin Research and Human Genetics, 2(2): 62-80.

Enger J. M., Howerton D. L, Cobbs C. R. 1994. Internal/External Locus of Control, Self-Esteem, and Parental Verbal Interaction of At-Risk Black Male Adolescents[J]. Journal of Social Psychology, 134(3): 269-274.

Fletcher J. M., Wolfe B. 2016. The importance of family income in the formation and evolution of non-cognitive skills in childhood[J]. Economics of Education Review, 54: 143-154.

Gatz M., Karel M. J. 1993. Individual Change in Perceived Control over 20 Years[J]. International Journal of Behavioral Development, 16(2): 305-322.

Gauly B. 2017. The Intergenerational Transmission of Attitudes: Analyzing Time Preferences and Reciprocity[J]. Journal of Family and Economic Issues, 38(2): 293-312.

Gong J., Lu Y., Xie H. 2017. Adolescent Environment and Noncognitive Skills. WorkingPaper. https://papers.ssrn.com/sol3/papers.cfm?abstract_id=2397046

Guo Z. 2002. The living Arrangement of the Oldest Old in China and Its Determinants[J]. Population Research, 1: 37-42. (in Chinese)

He Q., Li X., Wang R. 2018. Childhood Obesity in China: Does Grandparents' Coresidence Matter?[J]. Economics \& Human Biology, 29: 56-63.

Heckman J. J., Stixrud J., Urzua S. 2006. The Effects of Cognitive and Noncognitive Abilities on Labor Market Outcomes and Social Behavior[J]. Journal of Labor Economics, 24(3): 411-482.

Heckman J. J, Kautz T. 2012. Hard Evidence on Soft Skills[J]. Labour Economics, 19(4): 451-464.

Hernández-Alava M., Popli G.2017. Children's Development and Parental Input: Evidence from the UK Millennium Cohort Study[J]. Demography, 54(2): 485-511.

Jæger M. M. 2012. The Extended Family and Children's Educational Success[J]. American Sociological Review, 77(6): 903-922.

James-Burdumy S. 2005. The Effect of Maternal Labor Force Participation on Child Development[J]. Journal of Labor Economics, 23(1): 177-211.

Jiang H., Yang X. 2019. Parental Migration, Investment in Children, and Children's Non-cognitive 
Development: Evidence from Rural China. GLO Discussion Paper.No. 395.

Jung D-E, Bhang S-Y, Lee W-H, et al. 2018. Protective Role of Parenting Attitude on the Behavioral and Neurocognitive Development of the Children from Economically Disadvantaged Families[J]. Psychiatry investigation, 15(6): 584-592.

Khanam R., Nghiem S. 2016. Family Income and Child Cognitive and Noncognitive Development in Australia: Does Money Matter?[J]. Demography, 53(3): 597-621.

Kimball M. S., Sahm C. R., Shapiro M. D. 2009. Risk Preferences in the PSID: Individual Imputations and Family Covariation[J]. American Economic Review, 99(2): 363-368.

Kulas H. 1996. Locus of control in adolescence: a longitudinal study[J]. Adolescence, 31(123): 721-730.

Lassi G, Taylor A E, Mahedy L, et al. 2019. Locus of control is associated with tobacco and alcohol consumption in young adults of the Avon Longitudinal Study of Parents and Children[J]. Royal Society open science, 6(3): 181133.

Lee, L. and Park, A. 2010. Parental Migration and Child Development in China (Working Paper). Gansu Survey of Children and Families.

Liu A., Xie Y. 2015. Influences of Monetary and Non-monetary Family Resources on Children's Development in Verbal Ability in China[J]. Research in Social Stratification and Mobility, 40: $59-70$

Liu, B., Qing, P., Xiao, S. and Liao, F. 2019 The Influence of Grandparents' Indulgence on the Health Status of the Left-behind Children in Rural Areas from the Perspective of Food Consumption: A Case Study from Huber Province [J]. Chinese Rural Economy, 1: 32-46.(In Chinese)

Lumpkin J. R. 1986. The Relationship Between Locus of Control and Age: New Evidence[J]. Journal of Social Behavior and Personality, 1(2): 245-252.

McCauley E., Mitchell J. R., Burke P., et al. 1988. Cognitive Attributes of Depression in Children and Adolescents[J]. Journal of Consulting and Clinical Psychology, 56(6): 903-908.

McClun L. A., Merrell K. W. 1998. Relationship of Perceived Parenting Styles, Locus of Control Orientation, and Self - Concept among Junior High Age Students[J]. Psychology in the Schools,35(4): 381-390.

Mendolia S., Walker I. 2014. The Effect of Personality Traits on Subject Choice and Performance in High School: Evidence from an English Cohort[J]. Economics of Education Review, 43: 47-65.

Moilanen K. L., Shen Y-L. 2014. Mastery in Middle Adolescence: The Contributions of Socioeconomic Status, Maternal Mastery and Supportive-Involved Mothering[J]. Journal of Youth and Adolescence, 43(2): 298-310.

Nowicki S, Bliwise N, Joinson C. 2019. The Association of Children's Locus of Control Orientation and Emotion Recognition Abilities at 8 Years of Age and Teachers' Ratings of Their Personal and Social Difficulties at 10 Years[J]. Journal of Nonverbal Behavior, 43(3): 381-396.

Nowicki S., Gregory S., Iles-Caven Y., et al. 2018. Early Home-Life Antecedents of Children's Locus of Control[J]. Frontiers in psychology, 9: 2032.

Parrott C. A., Strongman K. T. 1984. Locus of Control and Delinquency[J]. Adolescence, 19(74): 459-471.

Phares E. J. 1976. Locus of control in personality[M]. Morristown: General Learning Press 
Morristown, 159.

Radl J., Salazar L., Cebolla-Boado H. 2017. Does Living in a Fatherless Household Compromise Educational Success? A Comparative Study of Cognitive and Non-cognitive Skills[J]. European Journal of Population, 33(2): 217-242.

Rotter J. B. 1966. Generalized Expectancies for Internal Versus External Control of Reinforcement[J]. Psychological monographs, 80(1): 1-28.

Ryckman R. M., Malikiosi M. X. 1975. Relationship between locus of control and chronological age[J]. Psychological reports, 36(2): 655-658.

Sadruddin A. F. A, Ponguta L. A., Zonderman A. L., et al. 2019. How do grandparents influence child health and development? A systematic review[J]. Social Science \& Medicine, 239: 112476.

Shi J, Wang L, Yao Y, et al. 2017. Family Function and Self-esteem among Chinese University Students with and without Grandparenting Experience: Moderating Effect of Social Support[J]. Frontiers in psychology, 8: 886.

Smetana J.G. 2017. Current Research on Parenting Styles, Dimensions, and Beliefs[J]. Current Opinion in Psychology, 15: 19-25.

Spokas M., Heimberg R. G. 2008. Overprotective Parenting, Social Anxiety, and External Locus of Control: Cross-sectional and Longitudinal Relationships[J]. Cognitive Therapy and Research, 33(6): 543-551.

Sun Y., Jiang N. J. 2017. The Effect of Grandparents' Co-parenting on Young Children's Personality and Adaptation: Chinese Three-generation-families[J].Asian Social Science, 13(5): 7-15.

Tanskanen A. O., Danielsbacka M. 2018. Multigenerational Effects on Children's Cognitive and Socioemotional Outcomes: A Within - Child Investigation[J]. Child Development, 89(5): 1856-1870.

Thompson A, Sullivan S, Lewis G, et al. 2011. Association between locus of control in childhood and psychotic symptoms in early adolescence: Results from a large birth cohort[J]. Cognitive Neuropsychiatry, 16(5): 385-402.

Wang, Y. 2013. An Analysis of the Changes in China's Urban and Rural Family Structures: Based on 2010 Census Data [J]. Social Sciences in China, 12: 60-77. (in Chinese)

Wang, Y. 2016. The "Separation" and "Unification" of Families, Households, and Homes in Contemporary China [J]. Social Sciences in China, 4: 91-110. (in Chinese)

Wu J., Zhang J. 2017. The Effect of Parental Absence on Child Development in Rural China[J]. Asian Economic Policy Review, 12(1): 117-134.

$\mathrm{Wu}$, Q. and Liu, B. Households and Child Development. In China People's Livelihood Development Report 2015, edited by Li, J. [M]. Beijing, Peking University Press 2015: 142-162. (in Chinese)

Yu H., Cao J., Kang S. 2019. Fertility Cost, Intergenerational Labor Division, and Female Employment[J].BOFIT Discussion Papers 14/2019.

Zhang H., Behrman J. R., Fan C. S., et al. 2014. Does parental absence reduce cognitive achievements? Evidence from rural China[J]. Journal of Development Economics, 111: 181-195.

Zhang, H., and Qin, X. 2019. The Impact of the Parenting Style on the Formation of Adolescent Human Capital [J]. Journal of Finance and Economics, 2: 46-58. (In Chinese) 
Table 1 Components of Locus of Control

\begin{tabular}{ll}
\hline \multicolumn{1}{c}{ Variable } & \multicolumn{1}{c}{ Survey Question } \\
\hline $\begin{array}{l}\text { Components of locus of } \\
\text { control }\end{array}$ & $\begin{array}{l}\text { Let } 0 \text { be the lowest score (least important), while } 10 \text { be the highest (most important).How } \\
\text { would you rate the importance of the following factors in a child's future success? Please } \\
\text { answer the following questions according to your own experience and opinion. }\end{array}$ \\
\hline Family Social Status & Q1.How important is the family social status to a child's future achievement? \\
Family Economic Condition & Q2.How important is the family economic condition to a child's future achievement? \\
Education & Q3.How important is the level of education to a child's future achievement? \\
Talent & Q4.How important is gifted talent to children's future achievement? \\
Effort & Q5.How important is effort to children's future achievement? \\
Luck & Q6.How important is luck to children's future achievement? \\
Family Social Connections & Q7.How important is family's social connections to children's future achievement? \\
\hline $\begin{array}{l}\text { Aggregated LOC indices } \\
\text { Full index }\end{array}$ & [Q1+ Q2 + Q4 + Q6 + Q7+ R(Q3 + Q5)]/7 \\
External index & (Q1+ Q2 + Q4 + Q6 + Q7)/5 \\
Internal index & (Q3 + Q5)/2 \\
\hline \hline
\end{tabular}

Source: Questionnaire of CFPS Data in 2010, 2012, and 2014.

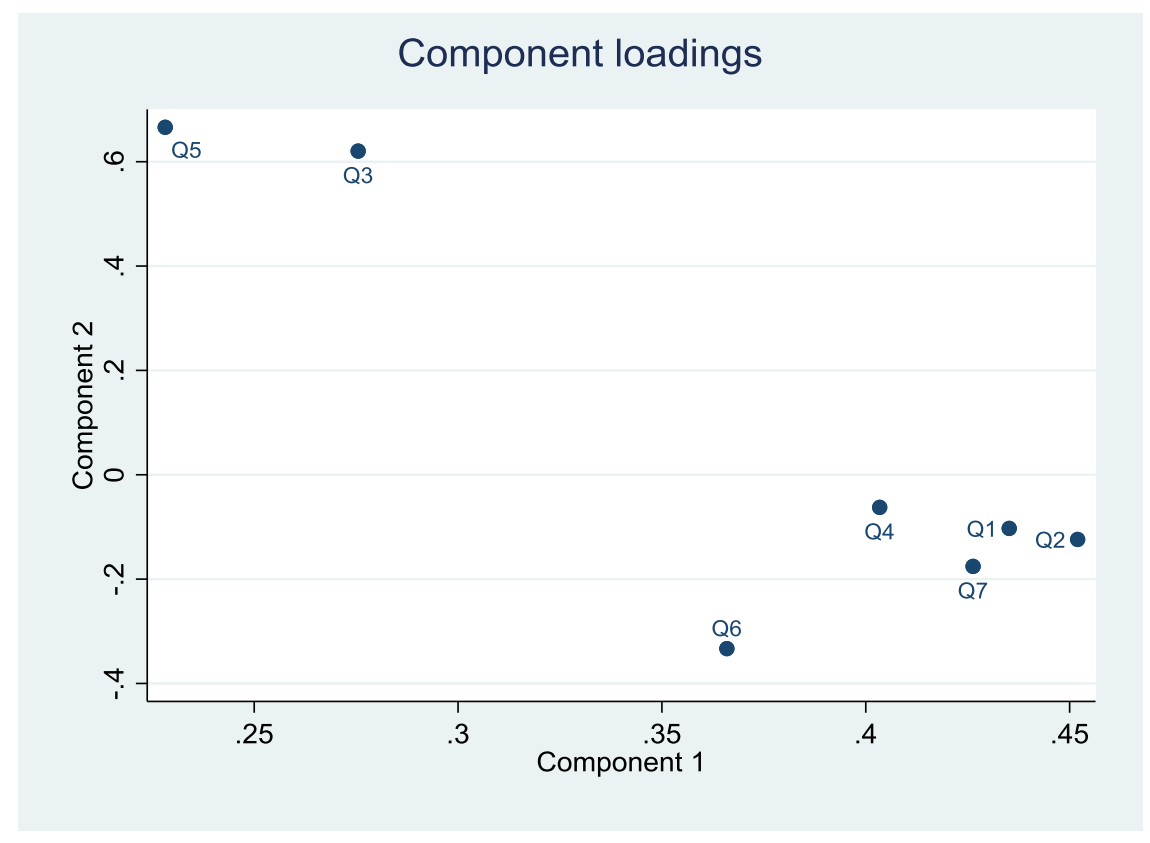

Figure 1 Factor Loadings of the Locus of Control Variables 
Table 2 Summary Statistics

\begin{tabular}{|c|c|c|c|c|c|c|}
\hline \multirow[b]{2}{*}{ Variables } & \multicolumn{3}{|c|}{ Full sample } & \multirow{2}{*}{$\begin{array}{l}\text { In the care of } \\
\text { grandparents } \\
\text { Mean }\end{array}$} & \multirow{2}{*}{$\begin{array}{l}\text { In the care of } \\
\text { parents } \\
\text { Mean }\end{array}$} & \multirow[t]{2}{*}{ Difference } \\
\hline & $\mathrm{N}$ & Mean & Std. Dev. & & & \\
\hline \multicolumn{7}{|l|}{ Panel A:Outcome variables } \\
\hline Full index & 4412 & 4.979 & 1.282 & 5.134 & 4.939 & $0.196 * * *$ \\
\hline External index & 4422 & 6.053 & 1.887 & 6.324 & 5.982 & $0.342 * * *$ \\
\hline Internal index & 4542 & 8.133 & 1.622 & 8.19 & 8.118 & 0.072 \\
\hline \multicolumn{7}{|l|}{ Panel B:Control variables } \\
\hline Child is a boy & 4598 & 0.523 & 0.5 & 0.527 & 0.522 & 0.005 \\
\hline Child lives in urban & 4589 & 0.393 & 0.489 & 0.404 & 0.39 & 0.014 \\
\hline Child's age & 4598 & 12.36 & 1.642 & 11.87 & 12.49 & $-0.617 * * *$ \\
\hline Child's education stage & 4534 & 2.397 & 0.543 & 2.29 & 2.425 & $-0.135 * * *$ \\
\hline No. of siblings of child & 4598 & 1.052 & 0.94 & 0.901 & 1.092 & $-0.191 * * *$ \\
\hline Father's years of education & 4561 & 7.327 & 4.209 & 7.914 & 7.175 & $0.739 * * *$ \\
\hline Mother's years of education & 4552 & 5.851 & 4.649 & 6.443 & 5.7 & $0.743 * * *$ \\
\hline Father's age & 4576 & 40.58 & 5.233 & 38.21 & 41.19 & $-2.983 * * *$ \\
\hline Mother's age & 4557 & 38.71 & 4.87 & 36.46 & 39.28 & $-2.821 * * *$ \\
\hline Household income per capita & 4587 & 8077 & 9086 & 8,644 & 7,931 & $713.527 * *$ \\
\hline Household size & 4589 & 4.868 & 1.688 & 5.609 & 4.676 & $0.933 * * *$ \\
\hline \multicolumn{7}{|l|}{ Panel C:Instrumental variables } \\
\hline No. of brothers of parents & 4598 & 1.177 & 1.162 & 0.924 & 1.243 & $-0.319 * * *$ \\
\hline No. of sisters of parents & 4598 & 2.349 & 1.85 & 1.802 & 2.492 & $-0.690 * * *$ \\
\hline \multicolumn{7}{|l|}{ Panel D:Potential channels } \\
\hline Primary caregiver's LOC & 4098 & 5.667 & 0.966 & 5.903 & 5.631 & $0.272 * * *$ \\
\hline $\begin{array}{l}\text { Primary caregiver's responsibility for the } \\
\text { child's academic grades }\end{array}$ & 2083 & 3.783 & 0.797 & 3.731 & 3.792 & -0.061 \\
\hline Caring about the child's schooling and life & 4274 & 3.288 & 0.727 & 3.104 & 3.317 & $-0.213 * * *$ \\
\hline $\begin{array}{l}\text { Positive response to the child's low school } \\
\text { grades }\end{array}$ & 4300 & 0.846 & 0.361 & 0.790 & 0.854 & $-0.065^{* * *}$ \\
\hline $\begin{array}{l}\text { Having family members tutored for } \\
\text { homework }\end{array}$ & 4451 & 0.437 & 0.496 & 0.423 & 0.440 & -0.018 \\
\hline Parents' communication with the child & 4426 & 3.636 & 0.754 & 3.531 & 3.662 & $-0.131 * * *$ \\
\hline
\end{tabular}


Table 3 Effects of Grandparental Care on Children's Locus of Control

\begin{tabular}{|c|c|c|c|c|c|c|c|}
\hline & First Stage & OLS & IV & OLS & IV & OLS & IV \\
\hline & $\begin{array}{c}\text { Grandparental } \\
\text { care }\end{array}$ & \multicolumn{2}{|c|}{ Full Index } & \multicolumn{2}{|c|}{ External Index } & \multicolumn{2}{|c|}{ Internal Index } \\
\hline Variables & (1) & (2) & (3) & (4) & (5) & (6) & (7) \\
\hline Grandparental care & & $\begin{array}{c}0.124 * * * \\
(0.042)\end{array}$ & $\begin{array}{c}1.135^{* * * *} \\
(0.366)\end{array}$ & $\begin{array}{c}0.116 * * * \\
(0.043)\end{array}$ & $\begin{array}{c}0.992 * * * \\
(0.346)\end{array}$ & $\begin{array}{l}-0.022 \\
(0.037)\end{array}$ & $\begin{array}{l}-0.257 \\
(0.304)\end{array}$ \\
\hline No. of brothers of parents & $\begin{array}{c}-0.029 * * * \\
(0.005)\end{array}$ & & & & & & \\
\hline No. of sisters of parents & $\begin{array}{c}-0.017 * * * \\
(0.003)\end{array}$ & & & & & & \\
\hline Child's age & $\begin{array}{c}-0.016^{* * *} \\
(0.005)\end{array}$ & $\begin{array}{c}-0.054 * * * \\
(0.014)\end{array}$ & $\begin{array}{c}-0.037 * * \\
(0.017)\end{array}$ & $\begin{array}{c}-0.044 * * * \\
(0.015)\end{array}$ & $\begin{array}{l}-0.028^{*} \\
(0.017)\end{array}$ & $\begin{array}{c}0.024 \\
(0.019)\end{array}$ & $\begin{array}{c}0.019 \\
(0.019)\end{array}$ \\
\hline Child's education stage & $\begin{array}{l}-0.007 \\
(0.015)\end{array}$ & $\begin{array}{c}-0.170 * * * \\
(0.042)\end{array}$ & $\begin{array}{c}-0.164 * * * \\
(0.044)\end{array}$ & $\begin{array}{c}-0.152 * * * \\
(0.043)\end{array}$ & $\begin{array}{c}-0.147 * * * \\
(0.044)\end{array}$ & $\begin{array}{c}0.041 \\
(0.052)\end{array}$ & $\begin{array}{r}0.040 \\
(0.052)\end{array}$ \\
\hline Child is a boy & $\begin{array}{c}0.012 \\
(0.012)\end{array}$ & $\begin{array}{c}0.050 \\
(0.032)\end{array}$ & $\begin{array}{c}0.037 \\
(0.035)\end{array}$ & $\begin{array}{c}0.048 \\
(0.032)\end{array}$ & $\begin{array}{c}0.036 \\
(0.034)\end{array}$ & $\begin{array}{l}-0.009 \\
(0.031)\end{array}$ & $\begin{array}{l}-0.006 \\
(0.032)\end{array}$ \\
\hline Child lives in urban & $\begin{array}{c}0.013 \\
(0.015)\end{array}$ & $\begin{array}{l}-0.032 \\
(0.041)\end{array}$ & $\begin{array}{l}-0.046 \\
(0.045)\end{array}$ & $\begin{array}{l}-0.046 \\
(0.040)\end{array}$ & $\begin{array}{l}-0.057 \\
(0.044)\end{array}$ & $\begin{array}{l}-0.036 \\
(0.043)\end{array}$ & $\begin{array}{l}-0.033 \\
(0.043)\end{array}$ \\
\hline No. of siblings of child & $\begin{array}{c}-0.079 * * * \\
(0.011)\end{array}$ & $\begin{array}{l}0.060 * * \\
(0.024)\end{array}$ & $\begin{array}{c}0.141 * * * \\
(0.038)\end{array}$ & $\begin{array}{l}0.051 * * \\
(0.024)\end{array}$ & $\begin{array}{c}0.121 * * * \\
(0.037)\end{array}$ & $\begin{array}{l}-0.021 \\
(0.021)\end{array}$ & $\begin{array}{l}-0.040 \\
(0.033)\end{array}$ \\
\hline Father's years of education & $\begin{array}{c}0.002 \\
(0.002)\end{array}$ & $\begin{array}{c}-0.018^{* * *} \\
(0.005)\end{array}$ & $\begin{array}{c}-0.021 * * * \\
(0.006)\end{array}$ & $\begin{array}{c}-0.015 * * * \\
(0.005)\end{array}$ & $\begin{array}{c}-0.017 * * * \\
(0.005)\end{array}$ & $\begin{array}{l}0.008 * \\
(0.005)\end{array}$ & $\begin{array}{l}0.009 * \\
(0.005)\end{array}$ \\
\hline Mother's years of education & $\begin{array}{l}-0.001 \\
(0.002)\end{array}$ & $\begin{array}{c}-0.021 * * * \\
(0.005)\end{array}$ & $\begin{array}{c}-0.021 * * * \\
(0.005)\end{array}$ & $\begin{array}{c}-0.019 * * * \\
(0.004)\end{array}$ & $\begin{array}{c}-0.018 * * * \\
(0.005)\end{array}$ & $\begin{array}{l}0.006 \\
(0.005)\end{array}$ & $\begin{array}{r}0.006 \\
(0.005)\end{array}$ \\
\hline Father's age & $\begin{array}{c}-0.006^{* * *} \\
(0.002)\end{array}$ & $\begin{array}{c}0.005 \\
(0.005)\end{array}$ & $\begin{array}{l}0.011^{*} \\
(0.006)\end{array}$ & $\begin{array}{c}0.004 \\
(0.005)\end{array}$ & $\begin{array}{c}0.009 \\
(0.006)\end{array}$ & $\begin{array}{l}-0.004 \\
(0.005)\end{array}$ & $\begin{array}{l}-0.006 \\
(0.005)\end{array}$ \\
\hline Mother's age & $\begin{array}{c}-0.005^{* *} \\
(0.002)\end{array}$ & $\begin{array}{l}-0.006 \\
(0.005)\end{array}$ & $\begin{array}{c}0.000 \\
(0.006)\end{array}$ & $\begin{array}{l}-0.007 \\
(0.005)\end{array}$ & $\begin{array}{l}-0.001 \\
(0.006)\end{array}$ & $\begin{array}{l}-0.001 \\
(0.005)\end{array}$ & $\begin{array}{l}-0.003 \\
(0.006)\end{array}$ \\
\hline Household income per capita & $\begin{array}{c}0.009 \\
(0.006)\end{array}$ & $\begin{array}{c}-0.036^{* * *} \\
(0.013)\end{array}$ & $\begin{array}{c}-0.047 * * * \\
(0.014)\end{array}$ & $\begin{array}{c}-0.030 * * \\
(0.014)\end{array}$ & $\begin{array}{c}-0.040 * * * \\
(0.014)\end{array}$ & $\begin{array}{c}0.015 \\
(0.014)\end{array}$ & $\begin{array}{c}0.017 \\
(0.014)\end{array}$ \\
\hline Household size & $\begin{array}{c}0.076^{* * *} \\
(0.009)\end{array}$ & $\begin{array}{c}0.004 \\
(0.011)\end{array}$ & $\begin{array}{c}-0.073^{* *} \\
(0.028)\end{array}$ & $\begin{array}{c}0.009 \\
(0.013)\end{array}$ & $\begin{array}{c}-0.057 * * \\
(0.026)\end{array}$ & $\begin{array}{c}0.016 \\
(0.013)\end{array}$ & $\begin{array}{c}0.034 \\
(0.025)\end{array}$ \\
\hline Survey wave dummies & Yes & Yes & Yes & Yes & Yes & Yes & Yes \\
\hline Province dummies & Yes & Yes & Yes & Yes & Yes & Yes & Yes \\
\hline Observations & 4417 & 4239 & 4239 & 4249 & 4249 & 4362 & 4362 \\
\hline K-P rk Wald F-stat. & & & 25.855 & & 26.105 & & 27.254 \\
\hline Hansen $\mathrm{J}$ test $\mathrm{P}$-value & & & 0.4904 & & 0.6134 & & 0.9354 \\
\hline
\end{tabular}

Notes: The full, external, and internal indexes are normalized by wave to obtain a mean of 0 and a standard deviation of 1 . Clustered standard errors at the county level are reported in parentheses. *, **, and *** represent statistical significance at the $10 \%, 5 \%$, and $1 \%$ levels, respectively. 
Table 4 Effects of Grandparental Care on Each Item of Children's Locus of Control

\begin{tabular}{|c|c|c|c|c|c|c|c|c|c|c|c|c|c|c|}
\hline & OLS & IV & OLS & IV & OLS & IV & OLS & IV & OLS & IV & OLS & IV & OLS & IV \\
\hline \multirow[t]{2}{*}{ Variables } & \multicolumn{2}{|c|}{ Family Social Status } & \multicolumn{2}{|c|}{$\begin{array}{c}\text { Family Economic } \\
\text { Condition }\end{array}$} & \multicolumn{2}{|c|}{ Talent } & \multicolumn{2}{|c|}{ Luck } & \multicolumn{2}{|c|}{$\begin{array}{c}\text { Family Social } \\
\text { Connections }\end{array}$} & \multicolumn{2}{|c|}{ Education } & \multicolumn{2}{|c|}{ Effort } \\
\hline & (1) & (2) & (3) & (4) & (5) & (6) & (7) & (8) & (9) & (10) & (11) & (12) & (13) & (14) \\
\hline \multirow[t]{2}{*}{ Grandparental childcare } & $0.173 * * *$ & $0.852 * * *$ & $0.111 * *$ & 0.610 & $0.072 *$ & 0.015 & 0.059 & $1.223 * * *$ & 0.011 & $0.585^{*}$ & -0.036 & 0.100 & 0.000 & $-0.586^{*}$ \\
\hline & $(0.045)$ & $(0.319)$ & $(0.045)$ & $(0.376)$ & $(0.038)$ & $(0.341)$ & $(0.044)$ & $(0.359)$ & $(0.040)$ & $(0.311)$ & $(0.038)$ & $(0.320)$ & $(0.040)$ & $(0.320)$ \\
\hline Other controls & Yes & Yes & Yes & Yes & Yes & Yes & Yes & Yes & Yes & Yes & Yes & Yes & Yes & Yes \\
\hline Survey wave dummies & Yes & Yes & Yes & Yes & Yes & Yes & Yes & Yes & Yes & Yes & Yes & Yes & Yes & Yes \\
\hline Province dummies & Yes & Yes & Yes & Yes & Yes & Yes & Yes & Yes & Yes & Yes & Yes & Yes & Yes & Yes \\
\hline Observations & 4316 & 4316 & 4365 & 4365 & 4360 & 4360 & 4391 & 4391 & 4350 & 4350 & 4376 & 4376 & 4397 & 4397 \\
\hline K-P rk Wald F-stat. & & 27.373 & & 26.344 & & 26.149 & & 27.795 & & 26.83 & & 27.253 & & 27.86 \\
\hline Hansen $\mathrm{J}$ test $\mathrm{P}$-value & & 0.9043 & & 0.4566 & & 0.5586 & & 0.2435 & & 0.9433 & & 0.7776 & & 0.5832 \\
\hline
\end{tabular}

Notes: Each item of locus of control is normalized by wave to obtain a mean of 0 and a standard deviation of 1. Other controls include a child's age, education stage, gender, living residence, and number of siblings; father's and mothers' years of schooling, father's and mother's ages, household income per capita, and household size. Clustered standard errors at the county level are reported in parentheses. *,**, and $* * *$ represent statistical significance at the $10 \%, 5 \%$, and $1 \%$ levels, respectively. 
Table 5 Effects of Grandparental Care on Children's Locus of Control (Main Caregiver Sample)

\begin{tabular}{|c|c|c|c|c|c|c|}
\hline \multirow[b]{3}{*}{ Variables } & OLS & IV & OLS & IV & OLS & IV \\
\hline & \multicolumn{2}{|c|}{ Full Index } & \multicolumn{2}{|c|}{ External Index } & \multicolumn{2}{|c|}{ Internal Index } \\
\hline & (1) & (2) & (3) & (4) & (5) & (6) \\
\hline \multirow[t]{2}{*}{ Grandparental childcare } & $0.127 * * *$ & $0.861 * * *$ & $0.131 * * *$ & $0.742 * *$ & 0.005 & -0.311 \\
\hline & $(0.047)$ & $(0.314)$ & $(0.049)$ & $(0.302)$ & $(0.044)$ & $(0.277)$ \\
\hline Other controls & Yes & Yes & Yes & Yes & Yes & Yes \\
\hline Survey wave dummies & Yes & Yes & Yes & Yes & Yes & Yes \\
\hline Province dummies & Yes & Yes & Yes & Yes & Yes & Yes \\
\hline Observations & 2930 & 2930 & 2940 & 2940 & 3028 & 3028 \\
\hline K-P rk Wald F-stat. & & 22.256 & & 22.533 & & 23.501 \\
\hline Hansen $\mathrm{J}$ test $\mathrm{P}$-value & & 0.5423 & & 0.3422 & & 0.5209 \\
\hline
\end{tabular}

Notes: The full, external, and internal indexes are normalized by year to obtain a mean of 0 and a standard deviation of 1. Other controls include a child's age, education stage, gender, urban residence, number of siblings; father's years of education, mother's years of education, father's age, mother's age, household income per capita, household size. Clustered standard errors at the county level are reported in parentheses. *, **, and *** represent statistical significance at the $10 \%, 5 \%$, and $1 \%$ levels, respectively.

Table 6 Effects of Grandparental Care on Children's Locus of Control (Primary Caregiver Sample)

\begin{tabular}{lcccccc}
\hline & OLS & IV & \multicolumn{2}{c}{ OLS } & IV & \multicolumn{2}{c}{ OLS } & IV \\
& \multicolumn{2}{c}{ Full Index } & \multicolumn{2}{c}{ External Index } & \multicolumn{2}{c}{ Internal Index } \\
Variables & $(1)$ & $(2)$ & $(3)$ & $(4)$ & $(5)$ & $(6)$ \\
\hline Grandparental childcare & $0.134 * * *$ & $1.249 * * *$ & $0.106^{* *}$ & $1.076^{* * *}$ & -0.067 & -0.341 \\
& $(0.049)$ & $(0.419)$ & $(0.050)$ & $(0.397)$ & $(0.048)$ & $(0.366)$ \\
Other controls & Yes & Yes & Yes & Yes & Yes & Yes \\
Survey wave dummies & Yes & Yes & Yes & Yes & Yes & Yes \\
Province dummies & Yes & Yes & Yes & Yes & Yes & Yes \\
Observations & 4137 & 4137 & 4147 & 4147 & 4256 & 4256 \\
K-P rk Wald F-stat. & & 27.26 & & 27.318 & & 28.537 \\
Hansen J test P-value & & 0.6092 & & 0.6334 & & 0.7723 \\
\hline
\end{tabular}

Notes: The full, external, and internal indexes are normalized by year, to obtain a mean of 0 and a standard deviation of 1 . Other controls include a child's age, education stage, gender, gender, urban residence, number of siblings; father's years of education, mother's years of education, father's age, mother's age, household income per capita, household size. Clustered standard errors at the county level are reported in parentheses. *, **, and *** represent statistical significance at the $10 \%, 5 \%$, and $1 \%$ levels, respectively. 
Table 7 Effects of Grandparental Care on Locus of Control (Including County Fixed Effects)

\begin{tabular}{|c|c|c|c|c|c|c|}
\hline \multirow[b]{5}{*}{ Variables } & OLS & IV & OLS & IV & OLS & IV \\
\hline & \multicolumn{6}{|c|}{ Full Index } \\
\hline & \multirow{2}{*}{\multicolumn{2}{|c|}{ Full Sample }} & \multirow{2}{*}{\multicolumn{2}{|c|}{ Main caregiver sample }} & \multirow{2}{*}{\multicolumn{2}{|c|}{$\begin{array}{c}\text { Primary caregiver } \\
\text { sample }\end{array}$}} \\
\hline & & & & & & \\
\hline & (1) & (2) & (3) & (4) & (5) & (6) \\
\hline \multirow[t]{2}{*}{ Grandparental childcare } & $0.105 * *$ & $1.134 * * *$ & $0.105^{* *}$ & $0.869 * *$ & $0.129 * * *$ & $1.246^{* * * *}$ \\
\hline & $(0.043)$ & $(0.369)$ & $(0.048)$ & $(0.342)$ & $(0.049)$ & $(0.411)$ \\
\hline Other controls & Yes & Yes & Yes & Yes & Yes & Yes \\
\hline Survey wave dummies & Yes & Yes & Yes & Yes & Yes & Yes \\
\hline Country dummies & Yes & Yes & Yes & Yes & Yes & Yes \\
\hline Observations & 4223 & 4223 & 2916 & 2916 & 4121 & 4121 \\
\hline K-P rk Wald F-stat. & & 26.083 & & 20.369 & & 31.567 \\
\hline Hansen $\mathrm{J}$ test P-value & & 0.3663 & & 0.4835 & & 0.5287 \\
\hline
\end{tabular}

Notes: The full, external, and internal indexes are normalized by year to obtain a mean of 0 and a standard deviation of 1 . Other controls include a child's age, education stage, gender, urban residence, number of siblings; father's years of education, mother's years of education, father's age, mother's age, household income per capita, household size. Clustered standard errors at the county level are reported in parentheses. *, **, and *** represent statistical significance at the $10 \%, 5 \%$, and $1 \%$ levels, respectively.

Table 8 Effects of Grandparental Care on Locus of Control (Including the Average Locus of Control within Family in Full Sample)

\begin{tabular}{|c|c|c|c|c|}
\hline \multirow[b]{3}{*}{ Variables } & OLS & OLS & IV & IV \\
\hline & \multicolumn{4}{|c|}{ Full Index } \\
\hline & (1) & (2) & (3) & (4) \\
\hline \multirow[t]{2}{*}{ Grandparental childcare } & $0.124 * * *$ & $0.094 * *$ & $1.135 * * *$ & $0.989 * * *$ \\
\hline & $(0.042)$ & $(0.042)$ & $(0.366)$ & $(0.353)$ \\
\hline \multirow[t]{2}{*}{ Locus of control of family } & & $0.167 * * *$ & & $0.141 * * *$ \\
\hline & & $(0.017)$ & & $(0.023)$ \\
\hline Other controls & Yes & Yes & Yes & Yes \\
\hline Survey wave dummies & Yes & Yes & Yes & Yes \\
\hline Province dummies & Yes & Yes & Yes & Yes \\
\hline Observations & 4239 & 4151 & 4239 & 4151 \\
\hline K-P rk Wald F-stat. & & & 25.855 & 22.385 \\
\hline Hansen $\mathrm{J}$ test $\mathrm{P}$-value & & & 0.4904 & 0.2945 \\
\hline
\end{tabular}

Notes: The full index is normalized by year to obtain a mean of 0 and a standard deviation of 1 . Other controls include a child's age, education stage, gender, urban residence, number of siblings; father's years of education, mother's years of education, father's age, mother's age, household income per capita, household size. Clustered standard errors at the county level are reported in parentheses. $* * *$, and $* * *$ represent statistical significance at the $10 \%, 5 \%$, and $1 \%$ levels, respectively. 
Table 9 Locus of Control and Age

\begin{tabular}{|c|c|c|c|}
\hline \multirow[b]{3}{*}{ Variables } & OLS & OLS & OLS \\
\hline & \multicolumn{3}{|c|}{ Full Index } \\
\hline & (1) & (2) & (3) \\
\hline \multirow[t]{2}{*}{ Age } & $0.007 * * *$ & & \\
\hline & $(0.001)$ & & \\
\hline \multirow[t]{2}{*}{ Age (above or equal to 50$)$} & \multirow{2}{*}{\multicolumn{3}{|c|}{$\begin{array}{c}0.141 * * * \\
(0.020)\end{array}$}} \\
\hline & & & \\
\hline \multirow[t]{2}{*}{ Age (above or equal to 60 ) } & & & $0.194 * * *$ \\
\hline & & & $(0.027)$ \\
\hline \multirow[t]{2}{*}{ Age (below 60 , above or equal to 50 ) } & & & $0.233 * * *$ \\
\hline & & & $(0.024)$ \\
\hline \multirow[t]{2}{*}{ Age (below 50, above or equal to 40 ) } & & & $0.222 * * *$ \\
\hline & & & $(0.024)$ \\
\hline \multirow[t]{2}{*}{ Gender } & $-0.028 * *$ & -0.013 & -0.020 \\
\hline & $(0.012)$ & $(0.012)$ & $(0.012)$ \\
\hline \multirow[t]{2}{*}{ Person Income（log） } & 0.002 & 0.001 & 0.000 \\
\hline & $(0.002)$ & $(0.002)$ & $(0.002)$ \\
\hline \multirow[t]{2}{*}{ Education years } & $-0.027 * * *$ & $-0.033 * * *$ & $-0.029 * * *$ \\
\hline & $(0.002)$ & $(0.002)$ & $(0.002)$ \\
\hline \multirow[t]{2}{*}{ Married } & 0.019 & $0.070 * * *$ & -0.024 \\
\hline & $(0.022)$ & $(0.022)$ & $(0.024)$ \\
\hline Family fixed effects & Yes & Yes & Yes \\
\hline Observations & 22857 & 22857 & 22857 \\
\hline
\end{tabular}

Notes: The full index is normalized to obtain a mean of 0 and a standard deviation of 1 . Clustered standard errors at the county level are reported in parentheses. *,**, and *** represent statistical significance at the $10 \%, 5 \%$, and $1 \%$ levels, respectively. 
Table 10 Intergenerational Transmission of Locus of Control (Primary Caregiver Sample)

\begin{tabular}{|c|c|c|c|c|}
\hline \multirow[b]{3}{*}{ Variables } & OLS & OLS & IV & IV \\
\hline & \multicolumn{4}{|c|}{ Full Index } \\
\hline & (1) & (2) & (3) & (4) \\
\hline Primary caregiver & $0.134 * * *$ & $0.122 * *$ & $1.249 * * *$ & $0.987 * *$ \\
\hline ( $1=$ grandparents, $0=$ parents $)$ & $(0.049)$ & $(0.053)$ & $(0.419)$ & $(0.435)$ \\
\hline \multirow[t]{2}{*}{$\begin{array}{l}\text { Locus of control of primary } \\
\text { caregiver }\end{array}$} & & $0.123 * * *$ & & $0.097 * * *$ \\
\hline & & $(0.017)$ & & $(0.024)$ \\
\hline Other controls & Yes & Yes & Yes & Yes \\
\hline Survey wave dummies & Yes & Yes & Yes & Yes \\
\hline Province dummies & Yes & Yes & Yes & Yes \\
\hline Observations & 4137 & 3799 & 4137 & 3799 \\
\hline K-P rk Wald F-stat. & & & 27.26 & 20.106 \\
\hline Hansen $\mathrm{J}$ test $\mathrm{P}$-value & & & 0.6092 & 0.3916 \\
\hline
\end{tabular}

Notes: The full index is normalized by year to obtain a mean of 0 and a standard deviation of 1 . Other controls include a child's age, education stage, gender, urban residence, number of siblings; father's years of education, mother's years of education, father's age, mother's age, household income per capita, household size. Clustered standard errors at the county level are reported in parentheses. ${ }^{*}, * *$, and $* * *$ represent statistical significance at the $10 \%, 5 \%$, and $1 \%$ levels, respectively.

Table 11 Differences in Parenting Attitudes and Style between Grandparents and Parents

\begin{tabular}{lccc}
\hline & OLS & OLS & OLS \\
& $\begin{array}{c}\text { Responsible for child's } \\
\text { academic grades }\end{array}$ & $\begin{array}{c}\text { Positive response to child's } \\
\text { low school grades }\end{array}$ & $\begin{array}{c}\text { Caring about child's } \\
\text { schooling and life }\end{array}$ \\
Variables & $(1)$ & $(2)$ & $(3)$ \\
\hline Primary caregiver & $-0.122^{*}$ & $-0.086^{* * *}$ & $-0.342^{* * *}$ \\
$\quad(1=$ grandparents, $0=$ parents $)$ & $(0.070)$ & $(0.019)$ & $(0.056)$ \\
Other controls & & Yes & Yes \\
Survey wave dummies & Yes & Yes & Yes \\
Province dummies & Yes & Yes & Yes \\
Observations & Yes & 4184 & 4175
\end{tabular}

Notes: Column (1) is based on a sample of children aged 10 to 15 years with either a grandparent or parent as the primary caregiver. Columns (2) and (3) are based on our primary caregiver sample. "Responsible for child's academic grades" and "Caring about child's schooling and life" are normalized by year to obtain a mean of 0 and a standard deviation of 1 . Other controls include a child's age, education stage, gender, urban residence, number of siblings; father's years of education, mother's years of education, father's age, mother's age, household income per capita, household size. Clustered standard errors at the county level are reported in parentheses. *, **, and *** represent statistical significance at the $10 \%, 5 \%$, and $1 \%$ levels, respectively. 
Table 12 Difference in Each Item of Caring for Children between Grandparents and Parents

(Primary Caregiver Sample)

\begin{tabular}{|c|c|c|c|c|c|c|}
\hline \multirow[b]{3}{*}{ Variables } & OLS & OLS & OLS & OLS & OLS & OLS \\
\hline & $\begin{array}{c}\text { Give up } \\
\text { watching TV }\end{array}$ & $\begin{array}{c}\text { Discuss } \\
\text { with child }\end{array}$ & $\begin{array}{l}\text { Ask child to } \\
\text { finish } \\
\text { homework }\end{array}$ & $\begin{array}{c}\text { Check } \\
\text { child's } \\
\text { homework }\end{array}$ & $\begin{array}{c}\text { Restrict } \\
\text { child from } \\
\text { watching } \\
\text { TV }\end{array}$ & $\begin{array}{l}\text { Restrict types of TV } \\
\text { programs child } \\
\text { could watch }\end{array}$ \\
\hline & (1) & (2) & (3) & (4) & $(5)$ & (6) \\
\hline Primary caregiver & -0.052 & $-0.363 * * *$ & $-0.156 * * *$ & $-0.413 * * *$ & $-0.099 *$ & $-0.136 * * *$ \\
\hline $\begin{array}{l}\quad(1=\text { grandparents, } \\
0=\text { parents })\end{array}$ & $(0.055)$ & $(0.060)$ & $(0.056)$ & $(0.056)$ & $(0.053)$ & $(0.051)$ \\
\hline Other controls & Yes & Yes & Yes & Yes & Yes & Yes \\
\hline Survey wave dummies & Yes & Yes & Yes & Yes & Yes & Yes \\
\hline Province dummies & Yes & Yes & Yes & Yes & Yes & Yes \\
\hline Observations & 4178 & 4202 & 4204 & 4203 & 4201 & 4199 \\
\hline
\end{tabular}

Notes: All dependent variables are normalized by year to obtain a mean of 0 and a standard deviation of 1 . Other controls include a child's age, education stage, gender, urban residence, number of siblings; father's years of education, mother's years of education, father's age, mother's age, household income per capita, household size. Clustered standard errors at the county level are reported in parentheses. *,**, and *** represent statistical significance at the $10 \%, 5 \%$, and $1 \%$ levels, respectively.

Table 13 Effects of Grandparental Care on Children's Family Environment (Full Sample)

OLS IV OLS IV

Having family members $\quad$ Parents actively communicate with tutored homework children

\begin{tabular}{ccccc} 
Variables & $(1)$ & $(2)$ & $(3)$ & $(4)$ \\
\hline Grandparental childcare & $-0.105 * * *$ & $-0.332 *$ & $-0.242 * * *$ & $-0.838^{* *}$ \\
& $(0.022)$ & $(0.184)$ & $(0.043)$ & $(0.412)$ \\
Other controls & Yes & Yes & Yes & Yes \\
Survey wave dummies & Yes & Yes & Yes & Yes \\
Province dummies & Yes & Yes & Yes & Yes \\
Observations & 4312 & 4328 & 4253 & 4253 \\
K-P rk Wald F-stat. & & 29.172 & & 26.127 \\
Hansen J test P-value & & 0.5578 & & 0.3308 \\
\hline
\end{tabular}

Notes: The outcome variable of "Parents actively communicate with children" is normalized by year to obtain a mean of 0 and a standard deviation of 1 . Other controls include a child's age, education stage, gender, urban residence, number of siblings; father's years of education, mother's years of education, father's age, mother's age, household income per capita, household size. Clustered standard errors at the county level are reported in parentheses. *, **, and $* * *$ represent statistical significance at the $10 \%, 5 \%$, and $1 \%$ levels, respectively. 


\section{Appendix: Estimation Results Based on Children Aged between 10 and 15 Years}

Table A1 Differences of Parenting Style between Grandparents and Parents

\begin{tabular}{lcc}
\hline & OLS & OLS \\
& $\begin{array}{c}\text { Positive response to child's } \\
\text { low school grades }\end{array}$ & $\begin{array}{c}\text { Caring about child's } \\
\text { schooling and life }\end{array}$ \\
Variables & $(1)$ & $(2)$ \\
\hline Primary caregiver & $-0.061^{* * *}$ & $-0.398^{* * *}$ \\
(1=grandparents, 0=parents $)$ & $(0.016)$ & $(0.043)$ \\
& & Yes \\
Other controls & Yes & Yes \\
Survey wave dummies & Yes & Yes \\
Province dummies & Yes & 7972 \\
Observations & 7960 & \\
\hline
\end{tabular}

Notes: The outcome of "Caring about child's schooling and life" is normalized by year to obtain a mean of 0 and a standard deviation of 1. Other controls include a child's age, education stage, gender, urban residence, number of siblings; father's years of education, mother's years of education, father's age, mother's age, household income per capita, household size. Clustered standard errors at the county level are reported in parentheses. *, **, and *** represent statistical significance at the $10 \%, 5 \%$, and $1 \%$ levels, respectively.

Table A2 Differences in Each Item of Caring for Children between Grandparents and Parents

\begin{tabular}{|c|c|c|c|c|c|c|}
\hline & OLS & OLS & OLS & OLS & OLS & OLS \\
\hline Variables & $\begin{array}{c}\text { Give up } \\
\text { watching TV }\end{array}$ & $\begin{array}{c}\text { Discuss } \\
\text { with child } \\
\text { (2) }\end{array}$ & $\begin{array}{l}\text { Ask child to } \\
\text { finish } \\
\text { homework } \\
\text { (3) }\end{array}$ & $\begin{array}{c}\text { Check } \\
\text { child's } \\
\text { homework } \\
\text { (4) }\end{array}$ & $\begin{array}{l}\text { Restrict } \\
\text { child from } \\
\text { watching } \\
\text { TV } \\
\text { (5) }\end{array}$ & $\begin{array}{l}\text { Restrict types of TV } \\
\text { programs the child } \\
\text { could watch } \\
\text { (6) }\end{array}$ \\
\hline Primary caregiver & $-0.099 * *$ & $-0.315^{* * *}$ & $-0.203 * * *$ & $-0.417 * * *$ & $-0.208 * * *$ & $-0.203 * * *$ \\
\hline $\begin{array}{l}\quad(1=\text { grandparents, } \\
0=\text { parents })\end{array}$ & $(0.038)$ & $(0.044)$ & $(0.039)$ & $(0.043)$ & $(0.041)$ & $(0.041)$ \\
\hline Other controls & Yes & Yes & Yes & Yes & Yes & Yes \\
\hline Survey wave dummies & Yes & Yes & Yes & Yes & Yes & Yes \\
\hline Province dummies & Yes & Yes & Yes & Yes & Yes & Yes \\
\hline Observations & 7987 & 8031 & 8033 & 8029 & 8023 & 8015 \\
\hline
\end{tabular}

Notes: All dependent variables are normalized by year to obtain a mean of 0 and a standard deviation of 1. Other controls include a child's age, education stage, gender, urban residence, number of siblings; father's years of education, mother's years of education, father's age, mother's age, household income per capita, household size. Clustered standard errors at the county level are reported in parentheses. *, **, and *** represent statistical significance at the $10 \%, 5 \%$, and $1 \%$ levels, respectively. 
Table A3 Effects of Grandparental Care on Children's Family Environment

\begin{tabular}{ccccc}
\hline & OLS & IV & OLS & IV \\
& \multicolumn{1}{c}{ Having family members } & \multicolumn{2}{c}{ Parents actively communicate with } \\
& tutored homework & \multicolumn{2}{c}{ children } \\
Variables & $(1)$ & $(2)$ & $(3)$ & $(4)$ \\
\hline Grandparental care & $-0.093^{* * *}$ & $-0.287^{* *}$ & $-0.241^{* * *}$ & $-0.609 *$ \\
Other controls & $(0.017)$ & $(0.140)$ & $(0.031)$ & $(0.331)$ \\
Survey wave dummies & Yes & Yes & Yes & Yes \\
Province dummies & Yes & Yes & Yes & Yes \\
Observations & 8214 & 8265 & Yes & Yes \\
K-P rk Wald F-stat. & & 38.006 & 7988 & 7988 \\
Hansen J test P-value & & 0.3622 & & 33.034 \\
\hline
\end{tabular}

Notes: Grandparental care is defined according to the definition in our full sample. The outcome of "Parents actively communicate with children" is normalized by year to obtain a mean of 0 and a standard deviation of 1 . Other controls include a child's age, education stage, gender, urban residence, number of siblings; father's years of education, mother's years of education, father's age, mother's age, household income per capita, household size. Clustered standard errors at the county level are reported in parentheses. *,**, and *** represent statistical significance at the $10 \%, 5 \%$, and $1 \%$ levels, respectively. 